\title{
Review
}

\section{Triacylglycerol hydrolase: role in intracellular lipid metabolism}

\author{
V. W. Dolinsky ${ }^{\dagger}$, D. Gilham, M. Alam, D. E. Vance and R. Lehner* \\ Departments of Pediatrics, Cell Biology and Biochemistry, CIHR Group on Molecular and Cell Biology of Lipids, \\ University of Alberta, 328 Heritage Medical Research Centre, Edmonton, Alberta T6G 2S2 (Canada), \\ e-mail: richard.lehner@ualberta.ca
}

Received 17 November 2003; received after revision 3 December 2003; accepted 9 February 2004

\begin{abstract}
Recent scientific advances have revealed the identity of several enzymes involved in the synthesis, storage and catabolism of intracellular neutral lipid storage droplets. An enzyme that hydrolyzes stored triacylglycerol (TG), triacylglycerol hydrolase (TGH), was purified from porcine, human and murine liver microsomes. In rodents, TGH is highly expressed in liver as well as heart, kidney, small intestine and adipose tissues, while in humans TGH is mainly expressed in the liver, adipose and small intestine. TGH localizes to the endoplasmic reticulum and lipid droplets. The TGH genes are
\end{abstract}

located within a cluster of carboxylesterase genes on human and mouse chromosomes 16 and 8 , respectively. TGH hydrolyzes stored TG, and in the liver, the lipolytic products are made available for VLDL-TG synthesis. Inhibition of TGH activity also inhibits TG and apolipoprotein B secretion by primary hepatocytes. A role for TGH in basal TG lipolysis in adipocytes has been proposed. TGH expression and activity is both developmentally and hormonally regulated. A model for the function of TGH is presented and discussed with respect to tissue specific functions.

Key words. Lipase; carboxylesterase; triacylglycerol; VLDL; liver; adipose; atherosclerosis.

\section{Neutral lipid storage}

The ability to store neutral lipids has a critical role in the ability of an organism to withstand fuel deprivation. Dysregulation of lipid synthesis and excessive lipid storage contributes to the development of diseases such as atherosclerosis, obesity and diabetes. Several excellent reviews regarding lipid storage have been published [1-3]. Most cells and tissues have the ability to synthesize and store neutral lipids as lipid droplets within the cytoplasm. This pool of stored lipid can serve specialized functions in different types of tissue. Heart and muscle store small

* Corresponding author.

${ }^{\dagger}$ Present address: Department of Physiology, University of Michigan, Ann Arbor, Michigan 48109-0622 (USA). quantities of triacylglycerol (TG) as a reservoir of fatty acids for oxidation in the working muscle [4]. Low-density lipoprotein (LDL) uptake and accumulation of neutral lipids by macrophages at the site of vascular injury promotes the development of atheromas [5]. The liver has adapted so that TG is stored in advance of its repackaging as lipoprotein particles, thereby regulating the rate of assembly and secretion in concert with the energy needs of the body [2]. Following a meal, the liver accumulates fatty acids from the circulation and stores them as TG. Later, in the post-absorptive state, stored TG is released by the liver as very low density lipoprotein (VLDL) [6]. White adipose tissue is quantitatively the most important tissue for the storage of TG. It serves as a reservoir for excess energy, as a heat insulator and now is recognized as an endocrine organ important to the regulation of energy 
intake through the secretion of hormones such as leptin, among others [7].

\section{Intracellular lipolysis of stored TG}

\section{Adipose tissue}

In order to derive energy in times of metabolic need, free fatty acids must be released from stored TG. Intracellular lipolysis in adipocytes is well described and may be grouped into two classes, hormonally regulated lipolysis and the relatively uncharacterized basal lipolysis.

In the adipocyte, hormone-stimulated lipolysis is catalyzed by hormone-sensitive lipase (HSL) that hydrolyzes cholesteryl ester (CE), as well as TG to diacylglycerol (DG) and DG to monoacylglycerol (MG) $[8,9]$. HSL is activated by lipolytic hormones such as catecholamines and glucagon, by a mechanism that involves a hormone/G-protein-induced increase in cyclic adenosine monophosphate (cAMP) that activates cAMP-dependent protein kinase (PKA) to phosphorylate HSL [10, 11]. Phosphorylation of HSL not only increases the activity of the enzyme but also causes HSL to translocate from the cytosol to the lipid droplet [12]. The mechanism of lipolytic stimulation also involves the lipid droplet surface protein, perilipin, which acts as a barrier in nonstimulated cells, preventing HSL access to the lipid droplet [13]. Perilipin overexpression promotes TG storage and decreases the rate of TG hydrolysis [14-16]. PKA phosphorylates perilipin and stimulates lipolysis, whereas mutation of the PKA phosphorylated sites on perilipin abolished the ability of lipolytic hormones to stimulate lipolysis $[15,17]$. Targeted deletion of the murine perilipin gene resulted in a lean mouse with higher rates of basal lipolysis and blunted hormone-stimulated lipolysis [18, 19]. Together, these results demonstrate that perilipin influences the ability of HSL to interact with the lipid droplet.

Previously, it was observed that differences in the rate of basal lipolysis among various fat depots in the rat paralleled the amount of HSL protein found in the respective fat depot [20]. Therefore, it was a surprise that HSL was not absolutely required for TG lipolysis in the adipose tissue from HSL null mice. Though hormonal stimulation of lipolysis was blunted both in vitro and in vivo, targeted deletion of the HSL gene reduced basal TG lipolysis $50 \%$, indicating that substantial residual TG lipase activity remained in HSL null adipocytes [21, 22].

\section{Liver}

The liver has the ability to store neutral lipids within droplets in the cytoplasm or secrete them into the circulation as apolipoprotein B (apoB)-containing VLDL particles. Several excellent reviews regarding the mechanism of VLDL assembly and secretion have been published
[23-25]. ApoB is translated on endoplasmic reticulum (ER) membrane-associated ribosomes. Hepatoma cells that require incubation with fatty acids in order to secrete lower-density apoB particles assemble fully lipidated particles in two distinct steps [26-28]. In the first step, apoB is partially lipidated with a small quantity of TG, CE, phospholipids and cholesterol forming a dense particle. The subsequent addition of the bulk of the neutral lipid to the small dense apoB particle results in a very low density apoB particle that is secreted into the circulatory system. The transcription and translation of apoB is continuous so that newly synthesized apoB is always available for assembly with lipids for secretion [29]. Translated and translocated apoB is also subject to intracellular degradation [30-32]. Lipid availability determines the percentage of apoB that is assembled into secretion-competent lipoprotein particles versus that which is misfolded and targeted for degradation [29, 30, 33]. A non-apoB-associated neutral lipid droplet that was identified by electron microscopy within the lumen of the smooth ER is thought to be a source of the bulk of the lipid for the nascent apoB particle [34]. The bulk lipidation of apoB has been reported to be complete before entering the Golgi apparatus in primary hepatocytes and in the rat hepatoma cell line McArdle RH7777 [35-37].

Exogenous fatty acids taken up by the hepatocyte are not directly utilized for TG secretion, but enter the intracellular storage pool as TG [38]. TG stored within the cytoplasmic lipid droplet of the hepatocyte is an important source of lipid for the lipoprotein particles that are secreted from the cell [6]. Several groups, using different experimental approaches, have quantitatively determined that the TG storage droplet within hepatocytes undergoes a cycle of lipolysis followed by reesterification. Wiggins and Gibbons [39] prelabeled the stored TG of cultured primary rat hepatocytes with ${ }^{3} \mathrm{H}$-oleate and ${ }^{14} \mathrm{C}$-glycerol and observed the distribution of the labeled TG over a subsequent 24-h chase period in the absence of exogenously supplied fatty acids. Two significant observations were made by this study: (i) A 70\% decline of the VLDLTG ${ }^{14} \mathrm{C}$ label indicated that the original TG-glycerol pool was diluted with unlabeled glycerol and (ii) the quantity of hydrolyzed TG that returned to the intracellular storage pool amounted to 1 pool per day, which was estimated to be $2-3$ times greater than required to maintain TG secretion. Since the original TG-glycerol pool was diluted with unlabeled glycerol, lipolysis and reesterification appeared to be essential for VLDL-TG assembly. Lankester et al. [40] used a dual labeling technique to differentiate between the incorporation of acyl chains into TG that were derived from exogenous and endogenous fatty acids. The authors observed exogenous ${ }^{14} \mathrm{C}$ fatty acids contributed only $\sim 17 \%$ of total acyl chains secreted as $\mathrm{TG}$, indicating that the majority of the acyl chains were derived from the prelabeled cytoplasmic TG stores. Stud- 
ies by Yang et al. [41, 42] showed that $60-70 \%$ of secreted TG was derived via lipolysis to DG followed by reesterification and $30-40 \%$ of secreted TG could have been derived from de novo TG synthesis. Overall, the data are consistent with a proportion of the TG stored within the liver undergoing lipolysis to DG/MG and then undergoing reesterification to form TG that is secreted as VLDL, or returned to storage pools in a futile cycle.

The hepatoma cell lines McArdle RH7777 and HepG2 primarily secrete TG that is derived from newly synthesized TG and are deficient in the mobilization of TG from the intracellular storage pools [43, 44]. Expression of the cytosolic lipase, HSL, in HepG2 cells directed fatty acids derived from labeled intracellular TG stores into the oxidative pathway as opposed to the secretory pathway [45], indicating that the subcellular localization of lipases may determine the fate of the lipolytic products. Furthermore, inhibition of lysosomal lipase by chloroquine did not affect the lipolysis of intracellular stored TG [39]. Since apoB-containing lipoproteins are assembled within the ER lumen, it is likely that the synthesis of TG for VLDL assembly must be directed towards that compartment. A lipase that mobilizes intracellular stored TG would likely be located within the ER in order to channel lipolytic products towards resynthesis to TG at the site of VLDL assembly. To that end, two candidate lipases localized to the microsomal fraction of the liver have been identified and termed a triacylglycerol hydrolase (TGH) [46] and arylacetamide deacetylase (AADA) [2]. The transfer of fatty acids into the ER lumen may occur by several possible mechanisms. One possibility is that lipolysis occurs at sites where the ER membrane is in contact with lipid droplets [47, 48]. At these contact points, lipolytic products would have increased solubility within the ER membrane and would be preferentially selected by the synthetic enzymes located within the ER membrane as opposed to being directed towards the oxidative pathway in the mitochondria [2].

\section{Purification, enzymology and structure of TGH}

TGH was initially purified from porcine liver microsomes [46]. Purified TGH had a high specific activity towards short-chain TGs and lower activity towards longerchain substrates [46]. It did not hydrolyze phospholipids or acyl-CoA thioesters [46]. Divalent cations were not required for optimal lipolytic activity of TGH. The lipolytic activity of purified TGH was inhibited by the serine-modifying chemicals diisopropyl fluorophosphate, diethyl $-p$ nitrophenylphosphate (E600) and tetrahydrolipstatin, indicating that TGH is a serine esterase [46, 49].

Amino-terminal sequences of the purified porcine TGH were found to be identical to that of porcine proline- $\beta$ naphthylamidase [50], which belongs to the carboxyl- esterase family of enzymes (EC 3.1.1.1). Several isoforms of carboxylesterases have been identified in mammalian tissues. These enzymes that hydrolyze chemically diverse substrates, including lipid esters and xenobiotic compounds, have been shown to have distinct biochemical, immunological and genetic properties (for a detailed review of carboxylesterases see [51]). Our group has cloned human [52], murine [53] and rat [44] TGH complementary DNAs (cDNA) that encoded mouse and rat proteins of 565 amino acids and a human protein of 568 amino acids (fig. 1). BLAST searches of GenBank and EMBL databases revealed that TGH is orthologous to the liver carboxylesterases of other species [51, 53]. The murine and human TGH proteins share $92 \%$ identity, and rat and human proteins share $93 \%$ identity at the amino acid level. The amino acid sequence of TGH has minimal identity to previously identified lipases, but more than $70 \%$ identity to carboxylesterases [53]. Further, phylogenetic analysis revealed that the TGH protein belongs to the CES1A class of carboxylesterases [51]. An alignment of orthologous murine, rat, rabbit, monkey and human TGH amino acid sequences showed that catalytic residues are conserved among a variety of mammalian species (fig. 1). TGH expression was immunodetected in livers from humans, rats, mice, hamsters and cows [49]. Given the number of different carboxylesterase proteins that have been described by different groups, a confusing number of names have been given to the TGH protein. For example, the carboxylesterase protein that is identical to rat TGH has been referred to as RL1 [54], ES10/pI 6.1 esterase [55], hydrolase A [56] and neutral cholesterol esterase [57]. For simplicity, we will refer to these identical proteins as TGH.

Several distinct structural and functional lipase/esterase motifs in the TGH amino acid sequence are apparent. The protein sequence has an N-terminal 18-amino acid signal peptide that directs protein synthesis into the lumen of the ER where TGH has been immunodetected $[46,49]$. The signal peptide is removed once inside the lumen by an ER-resident signal peptidase, as indicated by N-terminal sequencing of the purified protein [46]. The Ser221, Glu353 (354) and His466 (468) residues are highly conserved (fig. 1) and are predicted to form the TGH catalytic triad [51, 53, 58]. Two potential N-glycosylation sites were identified at Asn79 and Asn489 in the murine and rat TGH, while the human protein contains a single Asn 79 glycosylation site. The mature sequence of murine TGH contains four Cys residues, while the human TGH encodes an additional Cys at residue 390. The deduced protein sequence also contains a hydrophobic stretch of amino acids 414-429 that may be involved in lipid binding [59-64]. The C-terminal sequence HAEL in rat TGH has been proposed to function as the ER retrieval signal [65]. Similarly, the mouse HVEL and human HIEL C-terminal sequence TGH may be responsi- 

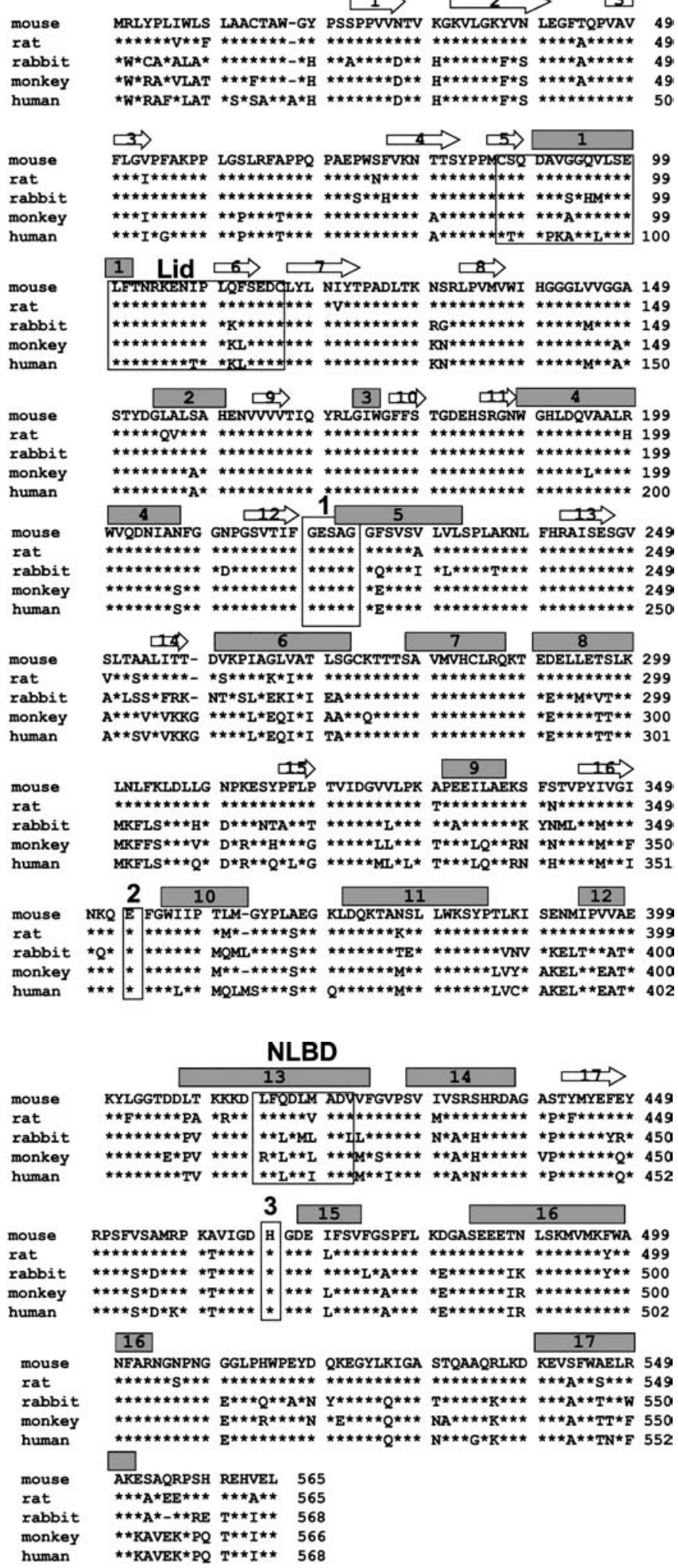

Figure 1. Alignment of amino acid sequences of proteins for the murine TGH with other mammalian liver carboxylesterases. The murine TGH single letter coding sequence is shown at the top. The sequences for rat, rabbit, monkey and human TGH are aligned below. Amino acid residues identical to the murine TGH are represented by an asterisk. Nonaligned residues are indicated by their single letter amino acid symbol. Thick arrows above the sequence indicate regions forming $\beta$ sheets in the murine TGH protein. Filled rectangles above the sequence indicate regions forming $\alpha$ helices in the murine TGH protein. Boxed residues indicate highly conserved residues. NLBD, putative neutral lipid binding domain; 1, GXSXG catalytic serine motif; 2, catalytic glutamic acid; 3 , catalytic histidine. 
ble for retention of the enzyme within the ER lumen (see below). Analysis of the murine and human TGH protein sequences with PSI-Pred and Predict Protein secondary structure prediction programs rendered a succession of strong and well-defined predictions for $17 \alpha$ helices and $17 \beta$ strands throughout the amino acid sequence (fig.1). In addition, these elements are strongly conserved among orthologous carboxylesterases from mouse, rat, rabbit, monkey and human. A three-dimensional model for human TGH has been proposed based on the crystal structure coordinates of acetylcholine esterase and overlapping active sites with pancreatic lipase ([58] and fig. 2 ). The modeled structure shares the overall folding and topology of the proteins identified in the recently published crystal structures of the rabbit [66] and human $[67,68]$ carboxylesterases. TGH has a three-dimensional $\alpha-\beta$ hydrolase fold that is a structural feature of all lipases [69]. In general, the structure of TGH may be viewed as comprising a central catalytic domain surrounded by $\alpha-\beta$ and regulatory domains [66-68]. In essence, the $\alpha-\beta$ hydrolase fold consists of a central $\beta$ sheet surrounded by a variable number of $\alpha$ helices and accommodates a catalytic triad composed of Ser, His and a carboxylic acid. The residues that compose the catalytic domain of human TGH are very highly conserved among orthologous TGH proteins from different species (fig. 1). This suggests that the catalytic function of these proteins is conserved across species. We have recently shown that mutation of any of Ser221, Glu354 or His468 of the human TGH to Ala abolishes TGH esterase activity [58]. Indeed, the role of these residues in catalysis is consistent with their orientation within the active site as suggested by our modeled structure of human TGH [58] and the crystal structures of rabbit [66] and human [67] carboxylesterases. The catalytic triad is located at the bottom of a deep active site cleft approximately in the center of the molecule and comprise a large flexible pocket on one side of Ser221 and a small rigid pocket on the opposite side (fig. 2).

The orientation and location of the active site provides an ideal hydrophobic environment for the hydrolysis of a wide variety of hydrophobic substrates. The small rigid active site pocket is adjacent to the oxyanion hole formed by Gly142/143 and is lined by several hydrophobic residues [67]. Short acyl chains would be easily accommodated within the small rigid pocket. The larger flexible active site pocket is lined by several nonpolar residues and could accommodate larger or polycyclic molecules such as cholesterol. The large pocket is adjacent to a sidedoor secondary pore that would permit small molecules (substrates and reaction products) to enter and exit the active site [67]. Longer acyl chains may be oriented for catalysis in such a way that they extend through the side door. Indeed, the presence of a hydrophobic residue at po-

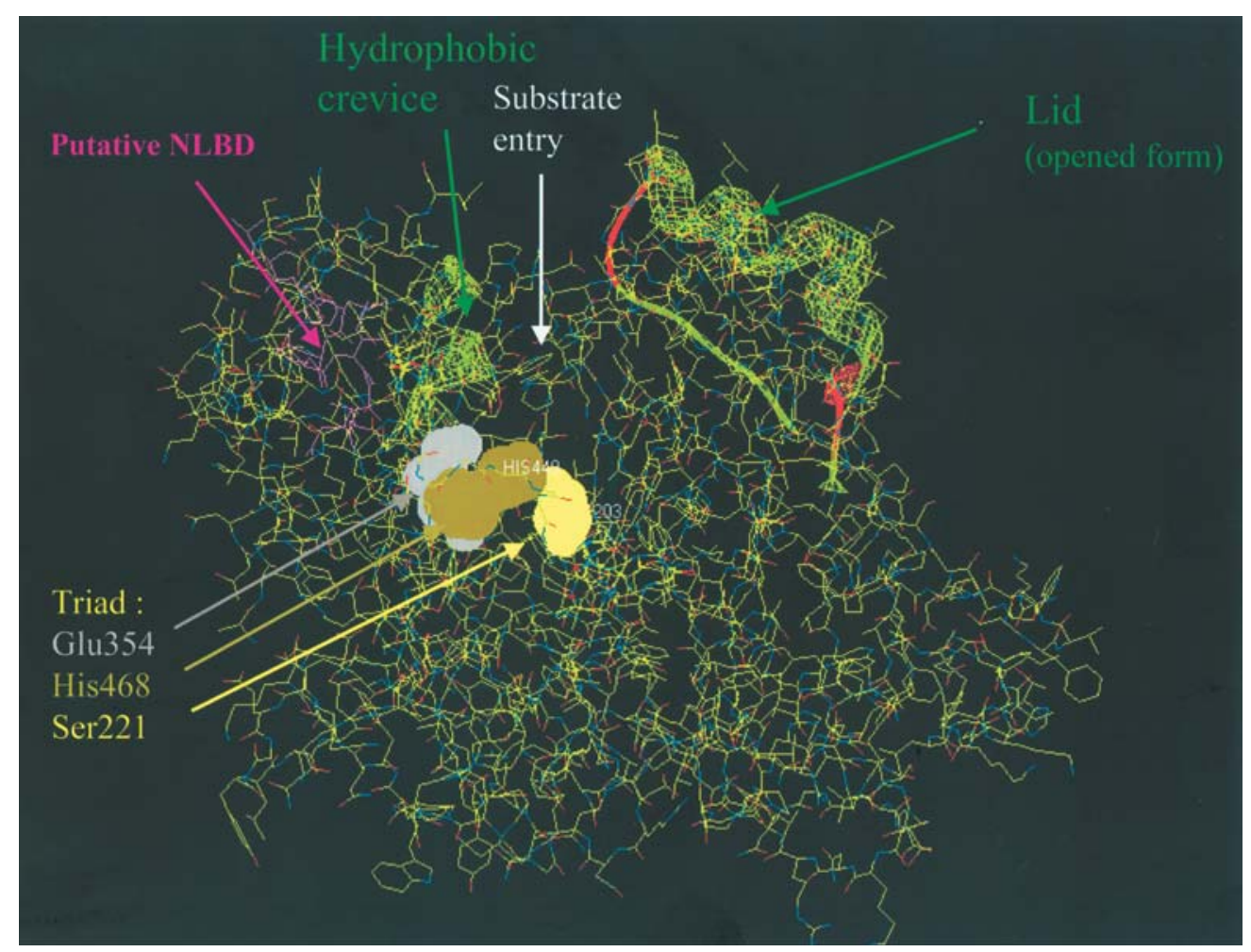

Figure 2. Three-dimensional model of human TGH based on coordinates obtained from crystal structures of acetylcholine esterase and pancreatic lipase. NLBD, putative neutral lipid binding domain. 
sition 423 in mouse and 425 in human is necessary for efficient hydrolysis of hydrophobic substrates, as mutation of Met present in position 423 of the related rat lung carboxylesterase to Ile increased the carboxylesterase activity towards a more hydrophobic substrate without affecting activity towards short-chain esters [70]. According to the X-ray crystal structure of the human carboxylesterase, this residue lines the flexible pocket adjacent to the side door [67]. Given the wide range of substrates that carboxylesterases are known to hydrolyze, the large flexible pocket confers the ability to hydrolyze many structurally distinct compounds, whereas the rigid pocket is much more selective with regard to the substrates that may be accommodated.

TG hydrolysis by TGH follows a two-step process that is supported by structural data [66] and is described for enzymes containing the $\alpha-\beta$ hydrolase fold by Ollies et al. [71]. Glu354 in TGH forms a low-energy hydrogen bond with His 468 that facilitates proton transfer from His 468 to Ser221 and nucleophilic attack by the Ser221 residue through stabilization of the tetrahedral intermediate. In addition, weak hydrogen bonds between peptide $\mathrm{N}-\mathrm{H}$ bonds of Gly141 and Gly142 act to stabilize the tetrahedral intermediate. In the second stage of catalysis, a proton is removed from His468, thereby forming an acyl-enzyme intermediate at Ser221. Once the alcohol product is released and substituted by a water molecule within the active site, a hydrolytic step occurs to release the fatty acid. Compounds other than water can attack the acyl-enzyme intermediate, leading to trans-esterification rather than hydrolysis (see below).

The entrance to the active site cleft of human TGH is surrounded by several $\alpha$ helices that define the regulatory domain that controls access of substrates to the TGH active site. $\alpha$ helix 1 (residues between Cys87 and Cys116) closes over the active site cleft and acts as a lid (figs 1,2). The amino acid sequence of the lid domain is highly conserved among orthologous TGH proteins, suggesting that it is necessary for TGH activity (fig. 1). The lid domain plays a vital role in lipolysis at the the lipid-water interface, by interfacial activation. In the absence of lipid-water interface the active site is covered by the lid. In the presence of hydrophobic substances the lid is opened and the catalytic site becomes accessible to the substrate. Interfacial activation kinetics were observed for both porcine and human TGH $[46,52]$. The $\alpha$ helix 13 contains a neutral lipid binding motif that is a potential determinant of the affinity of TGH for lipids (figs 1,2). The FLXLXXXn ( $\mathrm{n}=$ nonpolar amino acid residue) motif is present in several proteins that bind lipids [59-64]. The FLDLIADV lipid binding sequence is present in human TGH and shows conservation among orthologous TGH proteins (fig. 1). Four cysteine residues were identified in the mature mouse and rat TGH, and five in the human. Crystal structures indicate that Cys87 and Cys116 form one disulfide bridge and Cys273 and Cys284 form another disulfide bridge that stabilize the protein structure [67]. The Cys87-Cys116 disulphide bridge stabilizes the lid over the active site, contributing to substrate specificity and is apparently necessary for activity [67]. Because of these disulfide bonds, expression in Escherichia coli resulted in an inactive protein [52], as did expression in cytosol in mammalian cells by deletion of the signal sequence [unpublished results].

\section{Enzymatic activity of TGH}

The mammalian carboxylesterases compose a large multi-gene family that are characterized by their role in drug metabolism and detoxification and their ability to hydrolyze ester, thioester or amide bonds [51]. Some carboxylesterases were also shown to bind and retain proteins within a specific subcellular compartment [72-74]. Becker et al., [75] claimed that human TGH exhibited acyl-CoA:cholesterol acyltransferase (ACAT) activity, although subsequent studies have demonstrated that other proteins are responsible for catalyzing cholesterol esterification [76, 77]. Some rat carboxylesterases have been implicated in the hydrolysis of retinyl esters [78]. A rat carboxylesterase, identical to rat TGH, exhibited a fivefold increase in CE hydrolysis activity in the isolated cytosolic fraction when its cDNA was expressed in Cos-7 cells [57]. McArdle RH7777 cells require incubation with fatty acids in order to secrete lipids, unlike hepatocytes that continue to secrete lipids after fatty acids are withdrawn from the media [44]. Since McArdle RH7777 cells are deficient in the mobilization of TG from the intracellular storage pool [44], it is likely that fatty acids are trapped in the intracellular storage pool because these cells do not express TGH $[44,49]$. Rat TGH cDNA stably transfected into McArdle RH7777 cells resulted in depletion of the intracellular TG stores at a level two-fold higher than empty vector-transfected cells [44]. In addition, the secretion of TG into the medium was increased by $25 \%$, and the secretion of apoB 100 in the VLDL range was increased in rat TGH-transfected McArdle RH7777 cells compared with empty vector-transfected cells [44]. Moreover, inhibition of lipolysis by the irreversible serine esterase inhibitor E600 and by a specific TGH inhibitor, 4,4,4-trifluoro-2-[2-(3-methylphenyl)hydrozono]-1-(2thienyl)butane-1,3-dione, reduced the secretion of TG and apoB by primary rat hepatocytes and TGH stably transfected McArdle RH7777 cells [79]. The inhibitors had little effect on endogenous lipolytic activity in mocktransfected McArdle RH7777 cell microsomes, indicating the transfected TGH was the most active neutral lipase present [79]. Collectively, the evidence demonstrates that TGH is involved in the lipolysis of stored TG. Recently, several reversible inhibitors of TGH were iden- 
tified by a chemical proteomic strategy, termed activitybased protein profiling. Alkyl/aryl trifluoromethyl ketones proved to be the most selective and potent chemical inhibitors of TGH [80]. Others have identified tacrine derivatives that selectively inhibit human TGH but not other carboxylesterases [68]. The therapeutic potential of these compounds remains to be addressed.

In our hypothetical model of TG mobilization for VLDL assembly, TGH acts to hydrolyze TG in lipid storage droplets that are associated with the ER (fig. 3). The luminal lipid droplet is derived from de novo synthesized TG and from cytoplasmic TG stores in a process that involves microsomal TG transfer protein (MTP). Lipolysis of TG to DG/MG would make the lipolytic products more soluble in the membrane, thereby facilitating the efficient transfer of the acylglycerols for resynthesis to TG by luminally oriented acyltransferases and assembly into the nascent lipoprotein particle (fig. 3). TG that is not assembled onto apoB may be returned to either cytosolic or luminal storage pools in a futile cycle. Alternately, TGH may access TG from the cytosol-oriented ER-associated lipid droplet. Since TGH is luminally oriented, the mechanism via which the enzyme could access a cytosolic lipid droplet is not as obvious. It has been suggested [2] that this could occur after fusion of a cytosolic lipid droplet with the cytosolic leaflet of the ER membrane bilayer, as depicted in the figure 3 . The released fatty acids and partial acylglycerols may then serve as substrates for luminal TG synthesis or VLDL assembly.

In addition to its ability to hydrolyze lipids, TGH has been implicated in xenobiotic metabolism. TGH is one of a number of hepatic enzymes that can synthesize fatty acid ethyl esters in vitro, which are toxic metabolites of chronic alcohol consumption [81-83], as well as generate the toxic cocaine metabolite cocaethylene that is formed when cocaine and alcohol are taken together [84]. The X-ray crystal structure of human TGH bound to cocaine and heroine analogs provided structural insight into the ability of TGH to hydrolyze and inactivate these chemicals [67]. A great deal of effort has been placed on enhancing the cytotoxicity of the antitumor pro-drug irinotecan. The in vivo activation of irinotecan to the topoisomerase I inhibitor SN-38 (ethyl-10-hydroxycamptothecin) is catalyzed by carboxylesterases. Overexpression of human and murine TGH resulted in increased activation of irinotecan to $\mathrm{SN}-38$ and enhanced cytotoxicity in a variety of tumor cell lines [85-87]. However, these studies also showed that there are hepatic carboxylesterases with higher irinotecan hydrolytic activity than TGH.

\section{TGH gene and the carboxylesterase gene family}

Both the murine [54] and human [88, 89] TGH genes span $\sim 30 \mathrm{~kb}$ and contain 14 exons. Recently, sequencing of the mouse and human genomes were completed, enabling detailed sequence comparisons. The previously published sequences of the individual exons, splice junctions, size of the introns and restriction sites within the murine and human TGH genes are consistent with their respective genes sequenced by the mouse and human genome projects. Therefore, the organization of the TGH gene is evolutionarily conserved in mice and humans. Previous studies have mapped the human carboxylesterase gene to chromosome 16 at $16 \mathrm{q} 13-\mathrm{q} 22.1$ $[90,91]$. This region is syntenic to a region of mouse chromosome 8 at $8 \mathrm{C} 5$ [90]. The murine carboxylesterases Es22 [92, 93] and Es1 [94, 95] have been previously mapped to chromosome 8 . The completion of the mouse

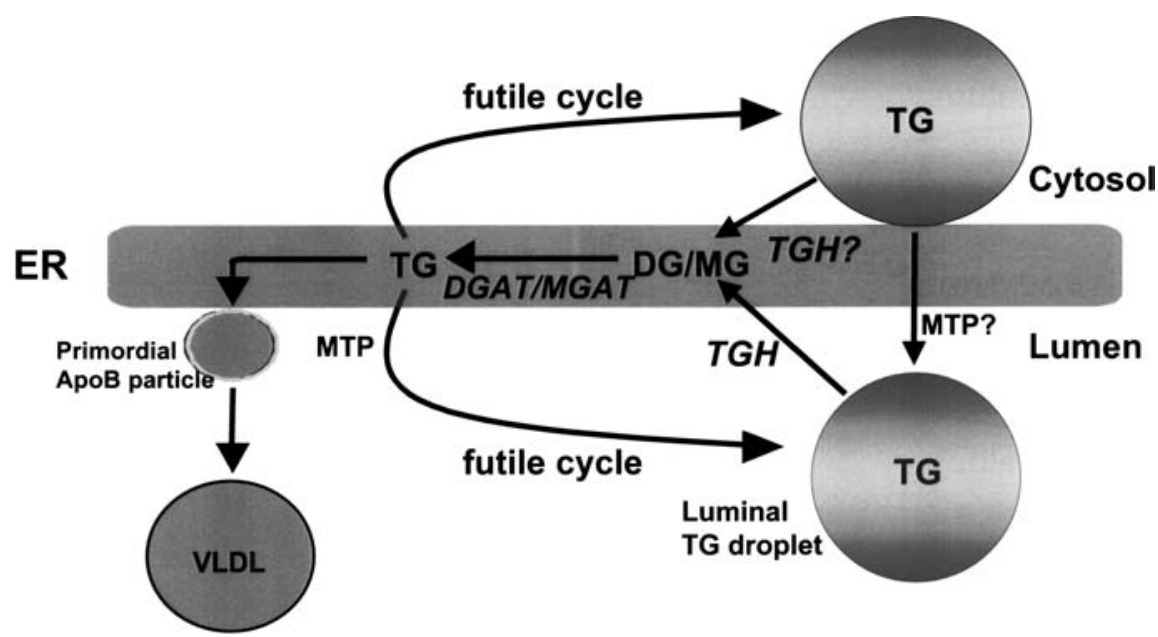

Figure 3. Proposed model of the role of TGH in apoB-containing lipoprotein assembly. MTP is involved in the formation of the luminal TG droplet that is mobilized for lipidation of apoB by TGH-catalyzed lipolysis and reacylation by the luminally oriented acyltransferases (MGAT/DGAT). TG not utilized for VLDL assembly is returned to the storage pool (futile cycle). 


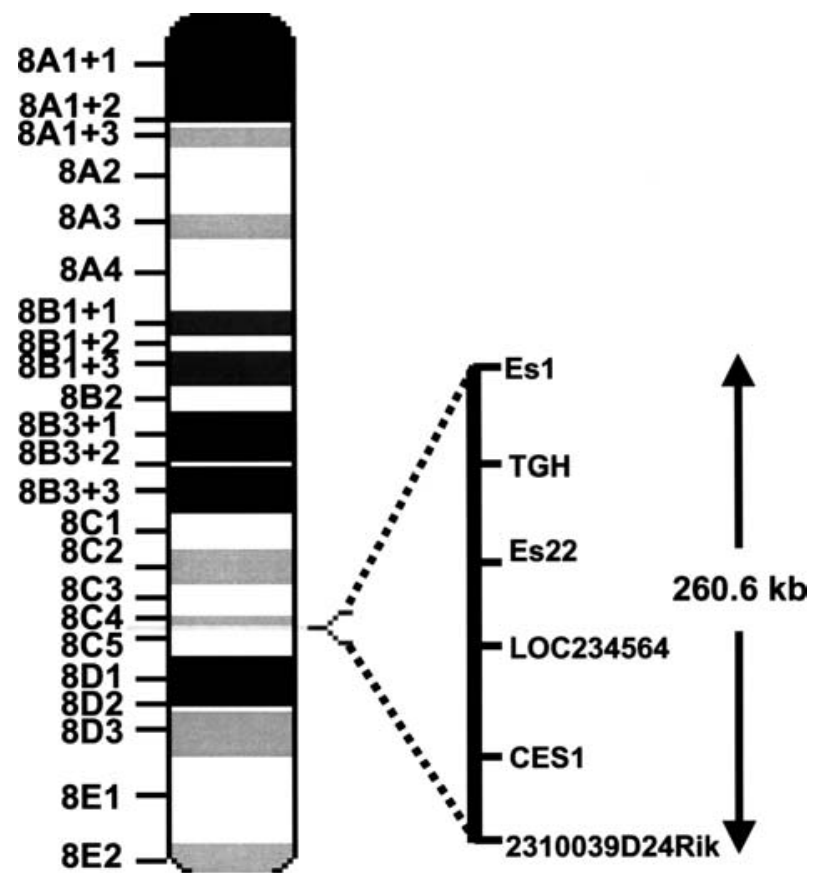

Figure 4. Chromosomal localization of the murine triacylglycerol hydrolase gene and the murine carboxylesterase gene cluster to chromosome $8 \mathrm{C} 5$.

genome sequencing project unambiguously demonstrated that the murine TGH gene was located on the minus strand of chromosome 8 at $8 \mathrm{C} 5$ in a cluster of six carboxylesterase genes that spans $260.6 \mathrm{~kb}$ in total (fig. 4). These six carboxylesterase genes are presumed to have originated from repeated gene duplications of a common ancestral gene that encoded a carboxylesterase [88, 96], and subsequent evolutionary divergence occurred. Evidence for their common ancestral origin comes from the shared structure and size of these genes. These genes encode proteins with significant identity to the other carboxylesterases encoded by genes within the cluster. The proteins encoded by Es22 [93] and CES1 [97] are most closely related, having $76 \%$ identity to murine $\mathrm{TGH}$, while M-LK has 70\% [87] and Es1 [95] has 69\% identity to TGH (fig. 5). A sixth gene, 2310039D24 Rik, does not code for a complete carboxylesterase protein. 2310039D24 Rik has identity to the 305 C-terminal residues of murine TGH, but does not contain the GXSXG catalytic serine motif. If this protein is expressed in a cell, it would not be expected to have esterase activity, and its putative function is obscure. The Ser, Glu and His catalytic residues were conserved in the remaining five carboxylesterase genes in the cluster, suggesting that they all have esterase activity [51]. The Es1 gene is composed of 13 exons and 12 introns, lacking an exon that encodes a loop and $\beta$ sheet in the other carboxylesterase genes (fig. 5) that form a portion of the active site cleft in the structure of TGH [67]. It is predicted that Es1 has a smaller active site cleft, making Es1 much more selective towards substrates that may be accommodated within the active site than the other carboxylesterases encoded by the gene cluster. In addition, the C-terminus of Es1 lacks an ER-retrieval sequence, causing the Es1 protein to be secreted, as has been demonstrated [98]. The most diverged region among the proteins encoded by the genes in the carboxylesterase cluster is located in the neutral lipid binding domain (NLBD) represented by the $\alpha$ helix 13 (figs 1,5 ). $\alpha$ helix 13 contains an FLXLXXXn motif in human TGH and LFQXLXXXn motif in murine TGH. This motif has been proposed to function in binding neutral lipids [58]. TGH, Es22 and CES1 are the only carboxylesterase genes in the cluster that encode a protein with similarities in the NLBD (fig. 5). Divergence in amino acid sequence among the murine carboxylesterases is also observed in the lid domain. The variability of amino acids in the NLBD and lid domains may be responsible for the differences in substrate selectivity and inhibition profiles of carboxylesterases encoded by genes in this cluster. At the moment, there is no experimental evidence that any of these carboxylesterases, besides TGH, hydrolyze lipid substrates or mobilize TG stored within the liver for secretion.

To measure the messenger RNA (mRNA) expression of individual carboxylesterases, reverse transcription polymerase chain reaction (RT-PCR) assay was designed that could accurately distinguish between TGH and the most closely related murine carboxylesterases, Es22 [93] and CES1 [97]. The ability of the specific primer set to amplify a target sequence was determined utilizing $20 \mathrm{ng}$ of the isolated cDNA sequence and reverse-transcribed liver mRNA. TGH-specific primers amplified the target sequence only from the murine TGH cDNA and a hepatic cDNA library and not murine Es22 or CES1 cDNAs (fig. 6A). Amplification of TGH was confirmed by sequencing the PCR product. In addition, Es22- and CES1-specific primers only amplified their respective cDNAs (table 1, fig. 6B, C). All primer sets amplified a target sequence from reverse-transcribed liver mRNA. Therefore, we have established specific assays to analyze the ex-

Table 1. PCR primers.

\begin{tabular}{ll}
\hline Gene & Primer \\
\hline DGAT1F & 5'-ATTCACGGATCATTGAGCG-3' \\
DGAT1R & 5'-CTGCCATGTCTGAGCATAGG-3' \\
DGAT2A & 5'-CTACGTTGGCTGGTAACTTCC-3' \\
DGAT2B & 5'-AACCAGATCAGCTCCATGG-3' \\
CES1F & 5'-CTATTCTTCCATGATGTGGCTCTGTG-3' \\
CES1R & 5'-CAAACATGACTGGGCCTCCTG-3' \\
Es22F & 5'-CCTGTAGCCTCCTACCATGTGC-3' \\
Es22R & 5'-GGGTGAGGCTGACAGAGTC-3 \\
TGHF & 5'-CACTGCTGCTCTGATTACAACAG-3' \\
TGHR & 5'-GCCTTCAGCGAGTGGATAGC-3' \\
CYC1A & 5'-TCCAAAGACAGCAGAAAACTTTCG-3' \\
CYC2B & 5'-TCTTCTTGCTGGTCTTGCCATTCC-3' \\
\hline
\end{tabular}




\begin{tabular}{|c|c|c|c|c|c|c|c|}
\hline TGH & MRLYPLIWLS & \multirow{2}{*}{$\begin{array}{l}\text { LAA-CTAWGY } \\
\star \star \star \text { FTAGA } \star H\end{array}$} & & KGKVLGKYVN & LEGETQPVAV & 49 \\
\hline Es22 & $\star C \star S A \star \star L V *$ & & \multicolumn{2}{|c|}{$\begin{array}{l}\text { PSSPPVVNTV } \\
\star \star \star \star \star \star M \star D * *\end{array}$} & 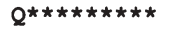 & $\approx \star \star \star \star \star \star$ & 50 \\
\hline M-LK & ${ }^{\star} F \star S T \star F L V *$ & $\star \star \star T-\star V I C \star N$ & \multicolumn{2}{|c|}{$\star \star \star \star \star \star \star \star \star D \mathrm{D} * \mathrm{~A}$} & 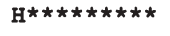 & $\mathrm{V}^{*} *$ & 49 \\
\hline CES1 & *W*CA SLI* & ${ }^{\star} T \star-\star L S L \star H$ & \multicolumn{2}{|c|}{$\star \star L \star \hbar \star \star \star * H * \star$} & $H * \star \star \star \star \star \star \star \star \star * T$ & 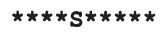 & 49 \\
\hline ES1 & *W*HV*VWA* & $\star \star V V-\star P I L * H$ & \multicolumn{2}{|c|}{$S L L * \star \star * \star D * T$} & $Q^{\star \star \star \star \star \star \star \star \star I S ~}$ & 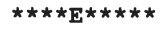 & 49 \\
\hline $\mathrm{GH}$ & FLGVPFAKPP & \multirow{2}{*}{$\begin{array}{l}\text { LGSLRFAPPQ } \\
\star \star \star \star \star \star \star \star \star \star\end{array}$} & \multicolumn{2}{|c|}{ PAEPWSFVKN } & TTSYPPMCSQ & DAVGGQVLSE & 99 \\
\hline$s 22$ & 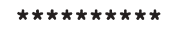 & & \multicolumn{2}{|c|}{ 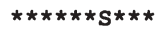 } & $A \star \star \star \star \star \star \star \star \star F^{\star}$ & $\star P \star T \star * I V N D$ & 100 \\
\hline M-LK & 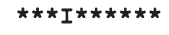 & 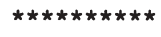 & \multicolumn{2}{|c|}{ 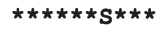 } & 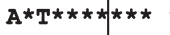 & $\star \star A R * \star A V N D$ & 99 \\
\hline CES1 & 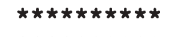 & 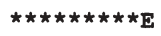 & \multicolumn{2}{|c|}{ 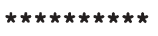 } & 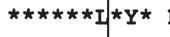 & NPEAALR $* A *$ & 99 \\
\hline ES1 & 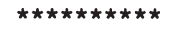 & 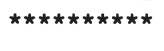 & \multicolumn{2}{|c|}{ 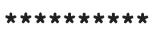 } & 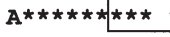 & ** GWAKI * SD & 99 \\
\hline CGH & LFTNRKENIP & LQFSEDCLYL & \multicolumn{2}{|c|}{ NIYTPADLTK } & MVWI & HGGG: & 149 \\
\hline Es22 & $\star \mathrm{L} * \star \star \star \star \star \mathrm{K} \star \star \star$ & \multirow{2}{*}{ 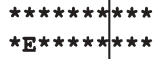 } & \multicolumn{2}{|c|}{ 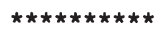 } & 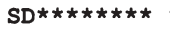 & 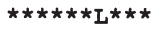 & 150 \\
\hline M-LK & $\star I * \star \star \star \star \star K \mathrm{~K} * \mathrm{H}$ & & \multicolumn{2}{|c|}{ 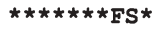 } & 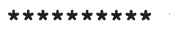 & 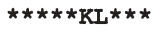 & 149 \\
\hline CES1 & * * * *QRKI * * & 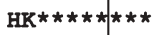 & \multicolumn{2}{|c|}{. } & 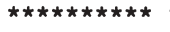 & 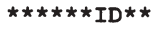 & 149 \\
\hline ES1 & $M * S T E * \star I L *$ & 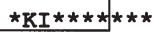 & \multicolumn{2}{|c|}{ 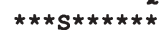 } & 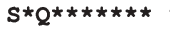 & $\star^{R} \mathrm{R}$ & 149 \\
\hline 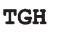 & STYDGLALSA & \multirow{2}{*}{$\begin{array}{l}\text { HENVVVVTIQ } \\
\star \star \star \star \star \star \star \\
* \star\end{array}$} & \multicolumn{2}{|c|}{ YRLGIWGFFS } & & GHI & 199 \\
\hline Es22 & 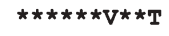 & & \multirow{2}{*}{\multicolumn{2}{|c|}{ 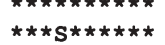 }} & $\star \star \star \star \star \star$ & 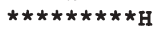 & 200 \\
\hline M-IK & 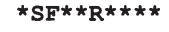 & 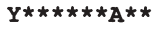 & & & 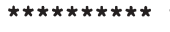 & 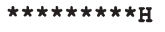 & 199 \\
\hline CES1 & 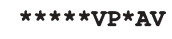 & 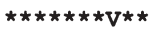 & \multicolumn{2}{|c|}{ 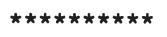 } & 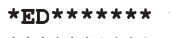 & 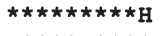 & 199 \\
\hline ES 1 & 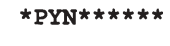 & 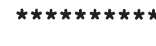 & & & 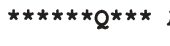 & 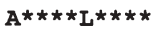 & 199 \\
\hline TGH & IFG & GNPGSVTIF & SAG & GFSVSV & LVLSPLAKNL & FHR & 249 \\
\hline Es22 & $\mathrm{K} \star \star$ & 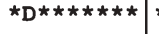 & & 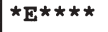 & 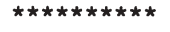 & 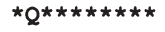 & 250 \\
\hline M-IK & 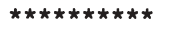 & 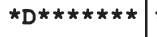 & $\star \star \star \star \star \star \star$ & $\star Y * \star \star I$ & $\star I * \star \star \star \star S * \star \star *$ & 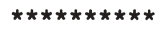 & 249 \\
\hline CESI & 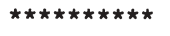 & 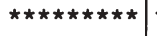 & $\approx \star \star$ & $\star \star \star \star \star \star \star$ & 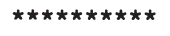 & 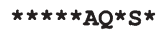 & 249 \\
\hline ES 1 & 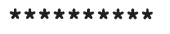 & 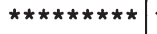 & $\star \star \star \star \star \star \star$ & 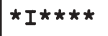 & $\star \star \star \star \star \star \star \star G \star D *$ & 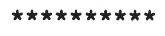 & 249 \\
\hline
\end{tabular}

SLTAALITTD VKPIAGLVAT LSGCKTTTSA VMVHCLRQKT EDELLETSLK 299

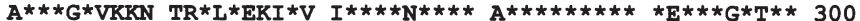

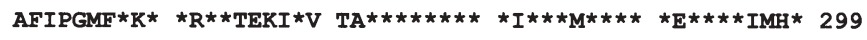

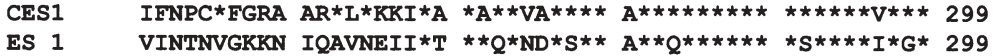

TGH LNLFKLDLLG NPKESYPFLP TVIDGVVLPK APEEILAEKS FSTVPYIVGI 349

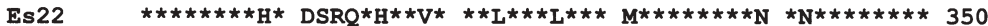

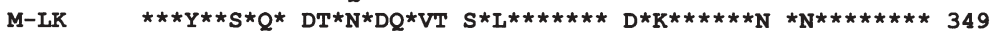

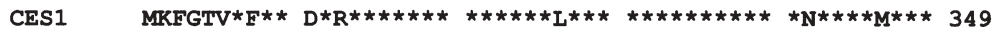

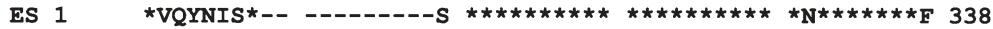

$$
2
$$

TGH NKQ E] FGWIIP TLMGYPLAEG KLDQKTANSL LWKSYPTLKI SENMIPVVAE 399

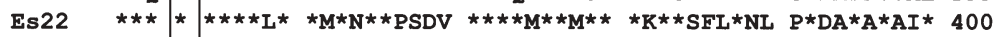

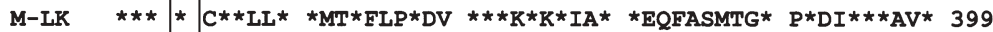

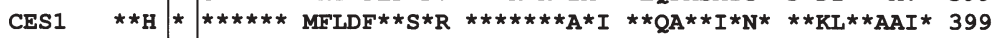

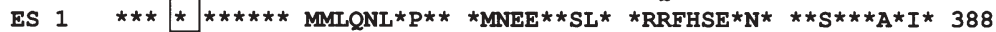

\section{NLBD}

\begin{tabular}{|c|c|c|c|c|c|c|c|}
\hline TGH & KYLGGTDDLT & KKKD & LFQDIM & ADVVFGVPSV & IVSRSHRDAG & ASTYMYEEEY & 449 \\
\hline Es22 & $\star \star \star R D K \star Y T G$ & $\mathrm{RN}^{*}$ * & QLLE*I & 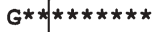 & 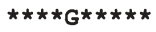 & 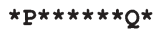 & 450 \\
\hline M-LK & $* \star T K * S * * P D$ & QIRE & GVL *A* & 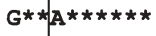 & $\star \star \star \star \star G \star * \star \star T *$ & $\star \mathrm{P} \star \star \star \star \star * Y \mathrm{Q}^{*}$ & 449 \\
\hline CES1 & 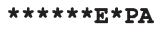 & TMT* & $\star \star I \star \star I I$ & 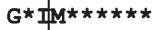 & 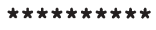 & 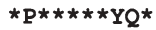 & 449 \\
\hline ES 1 & $\star \star \star R * V \star \star P I$ & $\star \star \mathrm{SE}$ & *IL *MF & 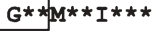 & 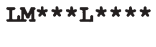 & 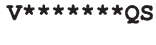 & 438 \\
\hline
\end{tabular}

TGH RPSFVSAMRP KAVIGD H GDE IFSVFGSPFL KDGASEEETN LSKMVMKFWA 499

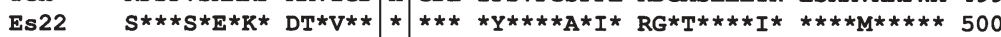

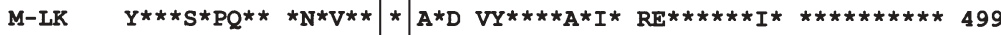

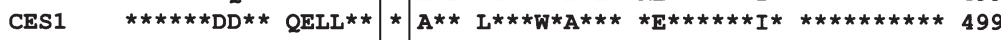

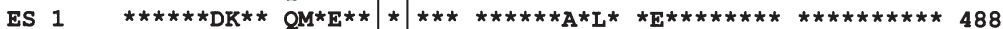

TGH NFARNGNPNG GGIPHWPEYD OKEGYIKIGA STOAAORIKD KEVSFWAFTR 549

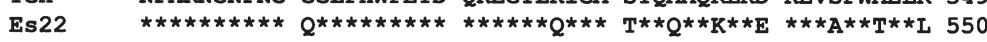

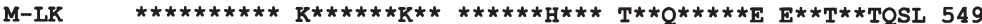

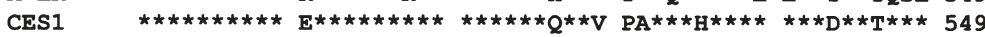

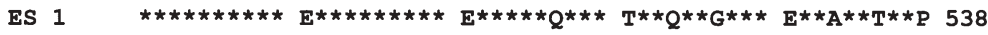

TGH AKESAQRPSH REHVEL 565

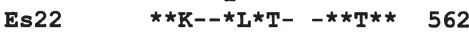

M-LK $\quad \star \star \mathrm{K}--\star \mathrm{PQP}-\quad-\mathrm{Y} * \mathrm{~N} \star \star * 561$

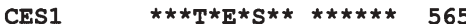

ES $1 \quad$ **NPPETDPT EHTEHK 554

Figure 5. Alignment of amino acid sequences of proteins encoded by the genes in the murine carboxylesterase gene cluster. The murine TGH single-letter coding sequence is shown at the top. The sequences for Es22, M-LK, CES1 and Es1 are aligned below. Amino acid residues identical to the murine TGH are represented by an asterisk. Nonaligned residues are indicated by their single-letter amino acid symbol. Boxed residues indicate highly conserved residues. NLBD, putative neutral lipid binding domain; 1, GXSXG catalytic serine motif; 2, catalytic glutamic acid; 3, catalytic histidine. 
cDNAs: TGH Es22 EsX Liver

A.

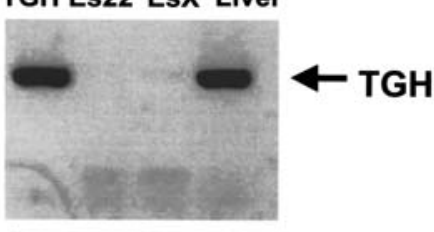

B.

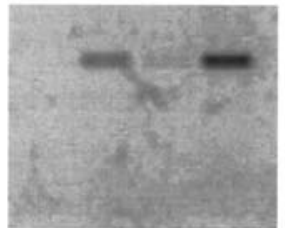

C.

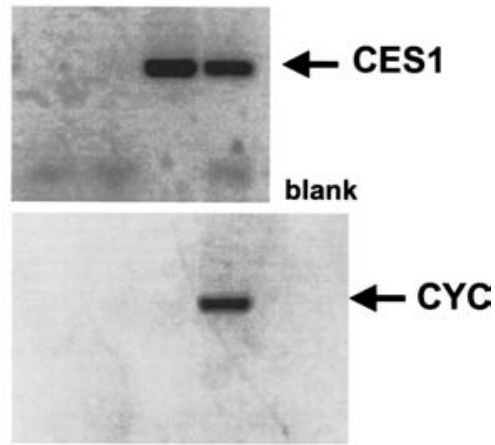

Figure 6. Positive control for specificity of RT-PCR analysis of carboxylesterase mRNA expression. The ability of primers specific for $(A) \mathrm{TGH}(B)$ Es22; $(C) \mathrm{CES} 1 ;(D)$ cyclophilin to amplify their target sequences ( 35 cycles) from either the TGH, Es22, CES1 cDNAs or a murine liver mRNA library.

pression of individual hepatic carboxylesterases. The ability to distinguish between individual carboxylesterase genes will be useful as we begin to explore whether hepatic carboxylesterases, in addition to TGH, hydrolyze stored lipids and examine whether these carboxylesterase genes are subject to individual mechanisms of regulation.

\section{Tissue expression of TGH}

TGH mRNA and protein are expressed predominantly in the liver, with lower levels in adipose, small intestine, kidney and heart [53]. TGH transcripts and protein were not detected in brain, spleen or skeletal muscle. These results agree with previous studies that have detected the highest level of TGH transcripts and protein in the liver $[54,56,87]$. In addition, lower levels of TGH transcripts and protein were detected in macrophages [99], heart [56, 87], kidney [87, 100], intestine [87], testis [87, 101] and adipose tissues [74].

\section{Function of TGH in the liver}

The high level of TGH expression within the liver is consistent with our hypothesis that TGH is involved in the

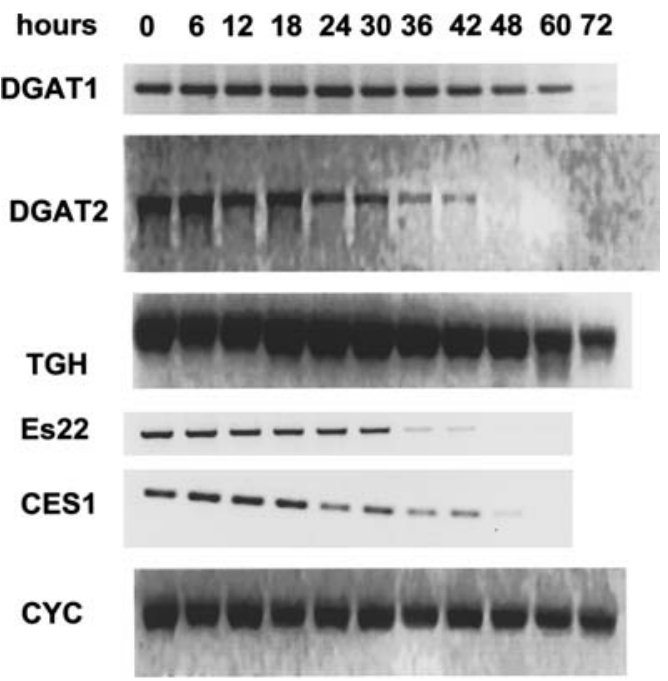

Figure 7. Expression of the enzymes of TG lipolysis and reesterification in hepatocyte cell cultures depends on the age of the culture. Cells derived from control mice were harvested at the indicated time points, and RNA was extracted. Cyclophillin (CYC), DGAT1, DGAT2, Es22, CES1 and TGH mRNA expression were detected by RT-PCR (40 cycles).

mobilization of intracellular TG stores for VLDL secretion $[44,79]$. Rat TGH could only be detected in liver parenchymal cells, but not Kupffer or endothelial cells [102]. Immunocytochemical studies localize TGH expression exclusively to adult hepatocytes surrounding the capillary vessels leading to the central vein [49]. This region of the liver is most likely to be active in lipoprotein production and secretion. The primary hepatocyte model is a well-characterized model for measuring the contribution of the lipolysis and reesterification pathway to TG secretion $[2,39]$. We determined by RT-PCR whether or not cultured primary murine hepatocytes express mRNAs for diacylglycerol acyltransferase (DGAT), TGH and other carboxylesterase enzymes that may be involved in TG lipolysis and reesterification, and followed the length of time in culture that hepatocytes maintained the expression of these mRNAs. DGAT1 mRNA expression could be detected up to $72 \mathrm{~h}$ in cell culture, but declined after $36 \mathrm{~h}$ (fig. 7). DGAT2 mRNA expression could be detected in hepatocytes up to $42 \mathrm{~h}$ in culture, but DGAT2 expression markedly declined after $30 \mathrm{~h}$ in culture (fig. 7). TGH mRNA is expressed for $72 \mathrm{~h}$, but its expression declines after $48 \mathrm{~h}$ (fig. 7). The other closely related carboxylesterases, Es 22 and CES1, were highly expressed in hepatocyte culture for $24 \mathrm{~h}$, after which their expression declined until it was no longer detectable beyond $48 \mathrm{~h}$ (fig. 7). Therefore, we have established that primary murine hepatocytes are an appropriate model for measuring intracellular TG lipolysis/reesterification up to $30 \mathrm{~h}$ in culture. This work is consistent with experiments of Bartlett and Gibbons that demonstrated that the rate of TG secretion by primary rat hepatocytes is linear for 
the first $24 \mathrm{~h}$ of culture and then declines markedly up to $72 \mathrm{~h}$ [103].

TGH may be associated with the main surface apolipoprotein component of VLDL, apoB. ApoB was crosslinked and immunoprecipitated with TGH (immunoprecipitated with anti-apoB, then mass spectral analysis [104] or immunoprecipitated with anti-apoB then Western blot of TGH [Gilham et al., unpublished]). Further, apoB-associated TGs on secreted particles from McArdle RH7777 cells are not substrates for TGH [105, D. Gilham et al., unpublished]. This suggests TGH is not delipidating apoB-containing particles during their assembly in the ER, despite residing in the same compartment. It is possible that TGH requires appropriate lipid droplet coat proteins to facilitate its interaction with a lipid substrate; however, apoB is not a compatible coat protein.

\section{Function of TGH in adipose tissue}

Adipose tissue forms large intracellular TG droplets. HSL is involved in the mobilization of fatty acids from adipocyte TG stores. However, targeted deletion of the HSL gene eliminated only $50 \%$ of the basal TG lipase activity of the adipocyte $[21,22]$. Currently, the only additional intracellular neutral TG lipase besides HSL identified within the adipocyte is TGH, suggesting involvement of TGH in the mobilization of fatty acids from adipocyte TG stores [53]. Inhibition of TGH reduced basal free fatty acid release by 3T3-L1 adipocytes and circulating free fatty acid levels in hamsters by $\sim 40 \%$ [W. Gao et al. and C. Borg-Capra et al., unpublished]. Therefore, TGH contributes a major proportion of adipocyte basal lipolysis.

\section{Function of TGH in other tissues}

TGH has been detected in the small intestine [46, 53]. High levels of TGH expression within murine duodenal/jejunal sections of the small intestine correspond to a previous report that MTP mRNA and protein expression were greatest in the duodenum and jejunum of the hamster small intestine [106]. We hypothesize that the expression pattern of TGH in the murine small intestine suggests a role for TGH in intestinal TG-rich, apoB-containing lipoprotein secretion. It has previously been shown that TG stored within the enterocyte undergoes a lipolysis reesterification cycle prior to TG secretion as an apoB particle [107] much as it does in the liver [39-41]. The kidney $[108,109]$ and heart $[110,111]$ have been shown to express MTP and possess the ability to secrete apoB-containing lipoproteins. However, a role for TGH in the secretion of TG-rich lipoproteins from these tissues remains to be demonstrated.
When loaded with cholesterol, macrophages accumulate CE-laden lipid droplets. Macrophages that invade the arterial wall and accumulate $\mathrm{CE}$ lead to the development of atherosclerotic lesions [5]. Removal of stored CE requires the activity of a neutral CE hydrolase, which may be limiting in macrophage foam cells. It has been reported that HSL is expressed in macrophages $[112,113]$. Overexpression of HSL in macrophages increased CE hydrolysis and cholesterol efflux [114, 115]. Furthermore, sterol loading of macrophages decreases HSL expression and CE hydrolase activity, suggesting that HSL represents the major intracellular CE hydrolase activity $[116,117]$. Though macrophage $\mathrm{CE}$ hydrolysis is unchanged in peritoneal macrophages from HSL null mice, it is unknown whether this is due to a compensatory upregulation of alternate $\mathrm{CE}$ hydrolase(s) [21, 118]. When human TGH was expressed in Cos cells, an increase in CE hydrolysis was observed [99]. Further, expression of TGH resulted in increased CE hydrolysis and efflux in $\mathrm{CHO}$ cells that have large intracellular $\mathrm{CE}$ stores due to ACAT1 overexpression [119]. However, if TGH has substantial CE hydrolase activity, the increased human TGH expression in sterol-loaded macrophages $[75,89]$ is not consistent with the observed decrease CE hydrolase activity $[116,117]$.

Several cDNAs and expressed sequence tags (ESTs) encoding TGH have been cloned from different tissues. In addition to the tissues where we detected TGH transcripts by Northern analysis, there is evidence for TGH expression in the mammary gland, skin, olfactory epithelium, salivary gland, eyeball, testis, ovary and uterus. A role for carboxylesterases in the fertility of a diverse group of organisms has been suggested [120], though a potential function for TGH in the other tissues is more obscure. The development of TGH null mice may provide more insight into what roles TGH activity contributes to these tissues.

\section{Regulation of TGH expression and activity}

\section{TGH promoter}

To investigate the transcriptional regulation of the TGH gene, human and murine TGH proximal promoters were isolated (fig. 8). The murine TGH promoter sequence [121] shares $59 \%$ identity to orthologous rat [122] and $46 \%$ identity to the human [89] TGH promoters. All three promoters share several common binding sites for transcription factors, suggesting that the orthologous TGH genes have evolutionarily conserved transcriptional regulatory patterns (fig. 8). A TATA box does not precede the transcription start site. Potential binding sites for transcription factors include three Sp1 binding sites, a NF-1, a peroxisomal proliferator-activated receptor response element and three sterol response element-like sequences. 

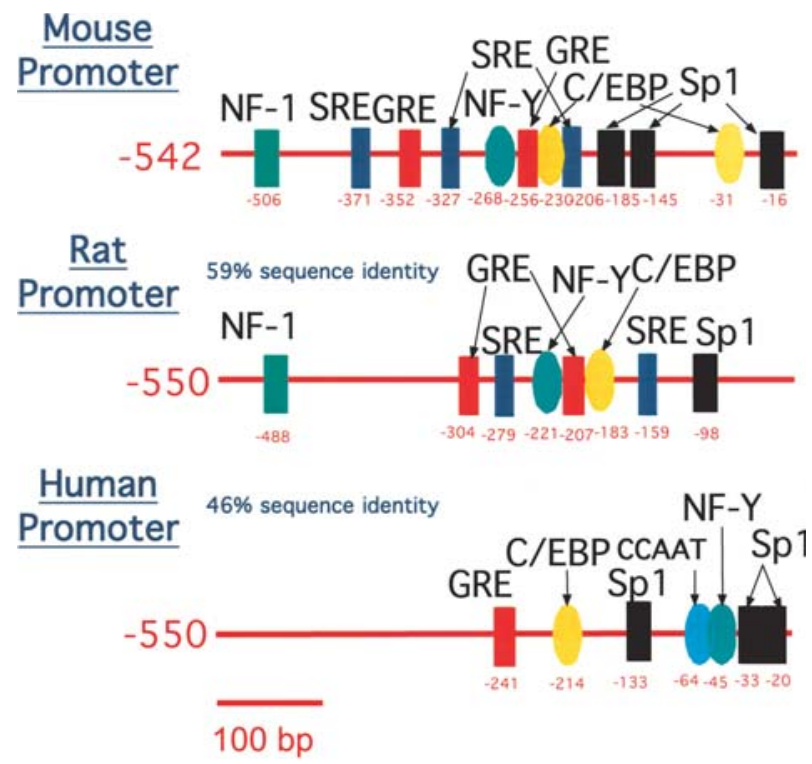

Figure 8. Putative transcription factor binding sites in the $5^{\prime}$-flanking region of the triacylglycerol hydrolase gene. The promoters were analyzed using the TRANSFAC database. Blue boxes represent sterol response elements, SRE; blue circles represent CCAAT box; red boxes represent glucocorticoid response elements halfsites, GRE; green boxes represent NF-1; green circles, NF-Y; black boxes, Sp1; and yellow circles represent CCAAT enhancer-binding protein, $\mathrm{C} / \mathrm{EBP}-\beta$.

Various studies observed increased expression of rat and mouse TGH mRNA and protein in the liver at the time of weaning, coincident with enhanced ability to secrete VLDL [49, 56, 121, 123]. This age-dependent expression appeared to be related to dietary changes at the time of weaning and independent of hepatic differentiation, since TGH expression was unchanged in regenerating liver that undergoes dedifferentiation and acquires fetal and neonatal features following partial hepatectomy [49].

The murine TGH promoter was utilized to determine whether the increased expression of TGH seen at the time of weaning was linked to transcriptional regulation and to identify potential transcription factors and cis-acting DNA elements that might mediate the observed developmental expression of TGH in liver. Electrophoretic mobility shift assays demonstrated enhanced binding to the murine TGH promoter of hepatic nuclear proteins from 27-day-old weaned mice compared with 7-day-old suckling mice [121]. DNase I footprint analysis localized binding of nuclear proteins to two regions within the promoter: site A, which contains a Sp1 binding site, and site $\mathrm{B}$, which contains a degenerate E-box [121]. Competitive electromobility shift and supershift assays demonstrated that site $\mathrm{A}$ binds $\mathrm{Sp} 1$ and $\mathrm{Sp} 3$ transcription factors and transcriptional activation assays in Schneider SL-2 insect cells demonstrated that $\mathrm{Sp} 1$ was a potent activator of the TGH promoter [121]. Sp1 is a ubiquitous nuclear protein that activates the transcription of a wide variety of genes
[124]. TATA-less promoters have been shown to be particularly sensitive to regulation by the Sp family of proteins $[125,126]$.

Alignment of the 5' proximal promoters of the murine, rat and human TGH genes demonstrated that regions termed $\mathrm{A}$ and $\mathrm{B}$ sequences are evolutionarily conserved [121]. Indeed, others have observed that reporter constructs containing the conserved site A sequence activate transcription, while their elimination reduces promoter activity $[89,122]$. A role for $\mathrm{Sp} 1$ in the phorbol ester-induced differentiation-dependent expression of human TGH in the macrophage THP-1 cell line has been demonstrated [127]. The transcription factor(s) that mediates the induction of murine TGH expression during 3T3-L1 adipocyte differentiation are not known [128], but are the subject of current investigation in our laboratory. Since TGH expression occurs at a late stage of adipocyte differentiation, clearly peroxisomal proliferator-activated receptor (PPAR) $y$ is potentially involved in the induction of TGH expression in mature 3T3-L1 adipocytes. We explored this possibility using a PPAR $y$ agonist that exhibited 1000 -fold selectivity over the other receptor isoforms [129]. Though TGH expression was increased when the PPAR $y$ agonist was present throughout the differentiation process, we did not observe a direct effect of PPAR $y$ on TGH expression [128].

\section{Regulation by fatty acids and sterols}

Both the degree of fatty acid saturation and the addition of cholesterol to a high fat diet modify the impact of the diet on lipid homeostasis. TGH expression was not affected by supplementation of the diet with $20 \%$ fatty acid, regardless of the degree of saturation [128]. Therefore, it appears that a high fat diet does not alter the level of hepatic TGH-mediated lipolysis.

PPARs are nuclear hormone receptors that utilize polyunsaturated fatty acids as natural ligands and regulate the expression of a range of genes involved in lipid metabolism (reviewed in [130]). PPAR $\alpha$ agonists, such as the fibrates, have beneficial effects on the plasma lipid profile through the increased oxidation of fatty acids, decreased circulating TG and reduced hepatic and adipose tissue TG storage [131]. Since TGH is involved in mobilizing fatty acids from stored TGs and the murine TGH promoter contains a single PPAR-like response element, we determined whether or not PPAR $\alpha$ agonists could regulate hepatic TGH expression in the mouse, utilizing wild-type and PPAR $\alpha$ null mice that had received clofibrate in their diet for 14 days. Hepatic TGH protein expression and microsomal esterase activity were not altered by clofibrate feeding or the targeted deletion of the PPAR $\alpha$ gene, supporting the idea that PPAR $\alpha$ does not directly regulate TGH mRNA expression [128]. Previously, 5 weeks of ex- 
posure to the PPAR $\alpha$ agonist WY-14,643 reduced the expression of murine liver TGH, though differences in TGH expression were not observed at 1 and 3 weeks of exposure [132]. Studies utilizing different peroxisomal proliferator compounds, doses and length of administration observed increased TGH expression in rats $[133,134]$ and mice $[133,135]$. It appears that the changes in TGH expression were observed only during long-term administration of a PPAR $\alpha$ agonist and reflect a secondary response.

Cholesterol feeding increased murine hepatic TGH expression approximately two-fold when diets were supplemented with fatty acids [128]. The observed induction of TGH expression in response to dietary fats supplemented with cholesterol is consistent with the observed induction of the orthologous human TGH expression by incubation of human macrophages with exogenous low-density lipoproteins [75, 89]. Hypercholesterolemic apoE null mice have a three-fold higher level of hepatic TGH expression than wild-type mice [136]. Chronic biliary diversion and feeding rats cholestyramine increased hepatic TGH expression two-fold [137]. Although sequences that bear some similarity to sterol response elements exist in the murine TGH proximal promoter, the functionality of these sequences has not been directly determined [121]. Sequences located within the 5'-upstream region of the rat TGH promoter have been demonstrated to act as sterol response elements in HepG2 cells and bind a purified sterol regulatory element-binding protein (SREBP)-2 transcription factor [122, 138]. However, the enforced expression of a nuclear form of SREBP-1a in transgenic mice failed to affect hepatic TGH mRNA expression [R. Lehner and D. E. Vance, unpublished]. Given these contrasting observations, it is unclear whether the cholesterol mediated regulation of TGH expression is due to SREBPs, oxysterol nuclear receptors or an indirect mechanism.

\section{Hormonal regulation of TGH}

We have demonstrated that hepatic TGH is subject to regulation by glucocorticoids in the mouse [139]. Glucocorticoids cause an increase in circulating TG and increased TG synthesis and storage [140-143]. Dexamethasone (Dex) is a potent analog of glucocorticoids (cortisol and corticosterone) and induces similar effects as natural glucocorticoids [143]. TGH mRNA, protein expression and hepatic microsomal esterase activity were decreased by Dex, whereas hepatic microsomal DGAT activity and DGAT-1 and -2 expression were increased [139]. This result correlates with decreased hepatic esterase activity and the results of others that have demonstrated that rat liver TGH expression was reduced by Dex [56, 144, 145]. We determined that the mechanism involved in the Dex- induced decline in TGH expression was a reduction in the mRNA stability of TGH [139]. Three AU-rich elements in the $3^{\prime}$-untranslated sequence of the murine TGH mRNA were necessary to mediate the destruction of the TGH mRNA in response to Dex [139]. The reduction of TGH expression resulted in a clear suppression of intracellular TG turnover in Dex-injected mice [139]. Since the rate of TG synthesis exceeded the rate of intracellular hepatic TG lipolysis as well as secretion, TG accumulated within the livers of Dex-injected mice. It is possible that these observations are relevant to diurnal changes in hepatic lipid synthesis and secretion that are associated with periodicity of circulating glucocorticoid levels [146-148]. For example, prior to a meal intake, glucocorticoid levels rise, and this would result in a decrease in hepatic TGH levels and a corresponding increase in lipogenic enzymes such as fatty acid synthase [149], microsomal phosphatidate phosphohydrolase-1 [150, 151], DGAT-1 and -2 [139]. Then, during the post-prandial period when circulating nonesterified fatty acid and chylomicron levels are high, the net synthesis of hepatic TG exceeds its disposal via secretion or oxidation, and there is a corresponding increase in hepatic lipid storage [152]. During the postabsorptive period, glucocorticoid levels fall, and this would correspond to a decreased rate of TG synthesis and increased hepatic TGH levels which would be required to utilize stored TG. In the post-absorptive period, hepatic TG secreted in VLDL particles originated from stored TG that had accumulated within the liver post-prandially [2]. Individuals that have elevated levels of glucocorticoids during the post-absorptive period store higher levels of hepatic TG $[153,154]$. Whether diurnal changes in TGH expression correlate with diurnal changes in circulating glucocorticoids will be a subject of further investigation. It appears, that increased de novo TG synthesis can overpower the normal regulation of VLDL secretion, as is observed in insulin-resistant states. We have also observed decreased white adipose tissue TGH expression in Dex-injected mice and this may contribute to obesity associated with elevated glucocorticoids [V. W. Dolinsky et al., unpublished]. It is unknown whether insulin can directly regulate TGH expression, though a recent report showed decreased TGH expression in the livers of mice with tumour necrosis factor- $\alpha$-induced insulin resistance [155]. A combination of increased TG synthesis and decreased TG lipolysis results in hepatic lipid accumulation and altered the balance between the utilization of stored TG versus de novo TG synthesis to supply TG for secretion.

\section{Post-translational regulation of TGH activity}

Two consensus sites for N-linked glycosylation have been identified at Asn79 and 489 in murine TGH and one at Asn79 in the human. Glycan detection assay of the human TGH indicates that the mature TGH protein 
was glycosylated [58]. However, mutation of Asn79 to Ala or Gln did not dramatically reduce human TGH activity, indicating that glycosylation was not necessary for esterase activity $[58,105$, D. Gilham et al., unpublished].

The primary sequence of human TGH contains a putative Tyr phosphorylation site at Tyr118, as well as seven potential Ser/Thr consensus sequences for phosphorylation by casein kinase II (CKII). The Tyr118 site is adjacent to the lid domain formed by the loop created by the disulfide bridge between Cys 87 and Cys116, potentially regulating the opening of the lid and entry of substrate into the catalytic cleft and the active site. Regulation of enzyme activity via this mechanism is an area of active study in our laboratory. Pertinent to TGH, several CKII target proteins such as the bile salt-dependent lipase are present in the ER lumen [156]. Reversible phosphorylation of rat TGH at Ser506 has been reported to increase CE hydrolase activity in isolated cytosolic fraction by $100-140 \%$ [70]. This mechanism of increased CE hydrolase activity in response to hormones associated with the fasted state (e.g. glucagon) is reminiscent of mobilization of TG and CE stores from adipose tissue by HSL. Phosphorylation of Ser506 is predicted to induce a conformational change that enhances binding of hydrophobic substrates, though the relevance of the regulation of rat TGH by phosphorylation is questionable, since Ser506 is not present in orthologous TGH amino acid sequences (fig. 1).

\section{Conclusions and future perspectives}

The recent characterization of TGH is a major advance since relatively little was known regarding the enzymes that catalyze the lipolysis of stored TG in tissues that do not express HSL. The experiments of our group and others demonstrate that $\mathrm{TGH}$ is a lipase, and it hydrolyzes stored TG in the hepatocyte.

The role of TGH in other tissues requires further investigation, though preliminary data suggests that TGH hydrolyzes stored TG within the adipocyte. Others have shown that TGH could hydrolyze various xenobiotic ester compounds as well as $\mathrm{CE}$ in cholesterol-laden cells. Given that the X-ray crystal structure explains the mechanism whereby TGH could hydrolyze various chemically diverse compounds, we suggest that endogenous TGH substrates within the cell are defined by the abundance of these molecules in a particular tissue as well as the accessibility to particular substrates as defined by the intracellular location of TGH. When the liver is challenged with xenobiotics, TGH could act in detoxification through the hydrolytic inactivation of these compounds. Given the large number of hepatic carboxylesterases expressed, further study will be required to identify the endogenous substrates and physiologic functions of these enzymes. Currently, we are determining whether other carboxylesterases and AADA, in addition to TGH, have the ability to hydrolyze intracellular stored TG. Ultimately, the transgenic mice overexpressing human TGH and mice harbouring a TGH null phenotype that are currently being developed in our laboratory will clarify the role of TGH in physiologic processes such as VLDL assembly.

Acknowledgements. Work on TGH was supported by grants from the Canadian Institutes of Health Research and GlaxoSmithKline. V. W. D. was supported by studentships from the Canadian Institutes of Health Research and the Alberta Heritage Foundation for Medical Research. D. G. is supported by the CIHR/HSFC/Industry SCOLAR Training Program. D. E. V. is a Heritage Medical Scientist and holds the Canada Research Chair on the Molecular and Cell Biology of Lipids. R. L. is a Medical Scholar of the Alberta Heritage Foundation for Medical Research.

1 Murphy D. J. and Vance J. (1999) Mechanisms of lipid-body formation. Tr. Biochem. Sci. 24: 109-115

2 Gibbons, G. F., Islam, K. and Pease, R. J. (2000) Mobilisation of triacylglycerol stores. Biochim. Biophys. Acta 1483: $37-53$

3 Murphy D. J. (2001) The biogenesis and functions of lipid bodies in animals, plants and microorganisms. Prog. Lipid Res. 40: $325-438$

4 Saddik M. and Lopaschuk G. D. (1991) Myocardial triglyceride turnover and contribution to energy substrate utilization in isolated working rat hearts. J. Biol. Chem. 266: $8162-8170$

5 Ross R. (1995) Cell biology of atherosclerosis. Ann. Rev. Physiol. 55: 791-804

6 Diraison F. and Beylot M. (1998) Role of human liver lipogenesis and reesterification in triglycerides secretion and in FFA reesterification. Am. J. Physiol. 274: E321-E327

7 Kim S. and Moustaid-Moussa N. (2000) Secretory, endocrine and autocrine/paracrine function of the adipocyte. J. Nutr. 130: $3110-3115$

8 Fredrikson G., Stralfors P., Nilsson N. O. and Belfrage P. (1981) Hormone-sensitive lipase of rat adipose tissue. J. Biol. Chem. 256: 6311-6320

9 Lee F. T., Adams J. B., Garton A. J. and Yeaman S. J. (1988) Hormone-sensitive lipase is involved in the hydrolysis of lipoidal derivatives of estrogens and other steroid hormones. Biochim. Biophys. Acta 963: 258-264

10 Walsh D. A., Perkins J. P. and Krebs E. G. (1968) An adenosine 3', $5^{\prime}$-monophosphate-dependant protein kinase from rabbit skeletal muscle. J. Biol. Chem. 243: 3763-3765

11 Stralfors P., Bjorgell P. and Belfrage P. (1984) Hormonal regulation of hormone-sensitive lipase in intact adipocytes: identification of phosphorylated sites and effects on the phosphorylation by lipolytic hormones and insulin. Proc. Natl. Acad. Sci. USA 81: 3317-3321

12 Clifford G. M., Londos C., Kraemer F. B., Vernon R. G. and Yeaman S. J. (2000) Translocation of hormone-sensitive lipase and perilipin upon lipolytic stimulation of rat adipocytes. J. Biol. Chem. 275: 5011-5015

13 Londos C., Brasaemle D. L., Gruia-Gray J., Servetnick D. A., Schultz C. J. et al. (1995) Perilipin: unique proteins associated with intracellular neutral lipid droplets in adipocytes and steroidogenic cells. Biochem. Soc. Trans. 23: 611-615

14 Brasaemle D. L., Rubin B., Harten I. A., Gruia-Gray J., Kimmel A. R. and Londos C. (2000) Perilipin A increases triacylglycerol storage by decreasing the rate of triacylglycerol hydrolysis. J. Biol. Chem. 275: 38486-38493 
15 Souza S. C., Muliro K. V., Liscum L., Lien P., Yamamoto M. T., Schaffer J. E. et al. (2002) Modulation of hormone-sensitive lipase and protein kinase A-mediated lipolysis by perilipin A in an adenoviral reconstituted system. J. Biol. Chem. 277: $8267-8272$

16 Tansey J. T., Huml A. M., Vogt R., Davis K. E., Jones J. M., Fraser, K. A. et al. (2003) Functional studies on native and mutated forms of perilipins. A role in protein kinase A-mediated lipolysis of triacylglycerols. J. Biol. Chem. 278: 84018406

17 Egan J. J., Greenberg A. S., Chang M. K. and Londos C. (1990) Control of endogenous phosphorylation of the major cAMP-dependent protein kinase substrate in adipocytes by insulin and beta-adrenergic stimulation. J. Biol. Chem. 265: $18769-18775$

18 Martinez-Botas J., Anderson J. B., Tessier D., Lapillone A., Chang B. H. J., Quast M. J. et al. (2000) Absence of perilipin results in leanness and reverses obesity in $\operatorname{Lepr}(\mathrm{db} / \mathrm{db})$ mice. Nat. Genet. 26: $474-479$

19 Tansey J. T., Sztalryd C., Gruia-Gray J., Roush D. L., Zee J. V., Gavrilova O. et al. (2001) Perilipin ablation results in a lean mouse with aberrant adipocyte lipolysis, enhanced leptin production, and resistance to diet-induced obesity. Proc. Natl. Acad. Sci. USA 98: 6494-6499

20 Sztalryd C. and Kraemer F. B. (1994) Differences in hormonesensitive lipase expression in white adipose tissue from various anatomic locations of the rat. Metabolism 43: 241-247

21 Osuga J.-I., Ishibashi S., Oka T., Yagyu H., Tozawa, R., Fujimoto A. et al. (2000) Targeted disruption of hormone-sensitive lipase results in male sterility and adipocyte hypertrophy, but not in obesity. Proc. Natl. Acad. Sci. USA 97: 787-792

22 Wang S. P., Laurin N., Himms-Hagen J., Rudnicki J., Levy E., Rober M. et al. (2001) The adipose tissue phenotype of hormone-sensitive lipase deficiency in mice. Obes. Res. 9: 119-128

23 Olofsson S. O., Asp L. and Boren J. (1999) The assembly and secretion of apolipoprotein B-containing lipoproteins. Curr. Opin. Lipidol. 10: 341-346

24 Shelness G. S. and Sellers J. A. (2001) Very-low-density lipoprotein assembly and secretion. Curr. Opin. Lipidol. 12: $151-157$

25 Gibbons G. F., Brown A. M., Wiggins D. and Pease R. (2002) The roles of insulin and fatty acids in the regulation of hepatic very-low-density lipoprotein assembly. J. R. Soc. Med. 95: $23-32$

26 Rustaeus S., Stillemark P., Lindberg K., Gordon D. and Olofsson S.-O. (1998) The microsomal triglyceride transfer protein catalyzes the post-translational assembly of apolipoprotein B-100 very low density lipoprotein in McA-RH7777 cells. J. Biol. Chem. 273: 5196-5203

27 Boren J., Rustaeus S. and Olofsson S.-O. (1994) Studies on the assembly of apolipoprotein B-100- and B-48-containing very low density lipoproteins in McA-RH7777 cells. J. Biol. Chem. 269: 25879-25888

28 Rustaeus S., Lindberg K., Boren J. and Olofsson S.-O. (1995) Brefeldin A reversibly inhibits the assembly of apoB containing lipoproteins in McA-RH7777 cells. J. Biol. Chem. 270: 28879-28886

29 Pullinger C. R., North J. D., Powell L. M., Wallis S. C. and Scott J. (1989) The apolipoprotein B gene is constitutively expressed in HepG2 cells: regulation of secretion by oleic acid, albumin, and insulin, and measurement of the mRNA halflife. J. Lipid Res. 30: 1065-1077

30 Borchardt R. A. and Davis R. A. (1987) Intrahepatic assembly of very low density lipoproteins. Rate of transport out of the endoplasmic reticulum determines rate of secretion. J. Biol. Chem. 262: 16394-16402

31 Sato R., Imanaka T., Takatsuki A. and Takano T. (1990) Degradation of newly synthesized apolipoprotein B-100 in a preGolgi compartment. J. Biol. Chem. 265: 1188-11884
32 Yao Z., Tran K. and McLeod R. S. (1997) Intracellular degradation of newly synthesized apolipoprotein B. J. Lipid Res. 38: $1937-1953$

33 White A. L., Graham D. L., LeGros J., Pease R. J. and Scott J. (1992) Oleate-mediated stimulation of apolipoprotein B secretion from rat hepatoma cells. A function of the ability of apolipoprotein B to direct lipoprotein assembly and escape presecretory degradation. J. Biol. Chem. 267: 15657-15664

34 Alexander C. A., Hamilton R. L. and Havel R. J. (1976) Subcellular localization of B apoprotein of plasma lipoproteins in rat liver. J. Cell Biol. 69: 241-263

35 Glaumann H., Bergstrand A. and Ericsson J. L. (1975) Studies on the synthesis and intracellular transport of lipoprotein particles in rat liver. J. Cell Biol. 64: 356-377

36 Cartwright I. J. and Higgins J. A. (1995) Intracellular events in the assembly of very-low-density-lipoprotein lipids with apolipoprotein B in isolated rabbit hepatocytes. Biochem. J. 310: $897-907$

37 Yamaguchi J., Gamble M. V., Conlon D., Liang J-S. and Ginsberg H. N. (2003) The conversion of apoB low density lipoprotein/high density lipoprotein particles to apoB100 very low density lipoproteins in response to oleic acid occurs in the endoplasmic reticulum and not in the Golgi in McA RH7777 cells. J. Biol. Chem. 278: 42643-42651

38 Gibbons G. F., Bartlett S. M., Sparks C. E. and Sparks J. D. (1992) Extracellular fatty acids are not utilized directly for the synthesis of very-low-density lipoprotein in primary cultures of rat hepatocytes. Biochem J. 287: 749-753

39 Wiggins D. and Gibbons G. F. (1992) The lipolysis/esterification cycle of hepatic triacylglycerol. Its role in the secretion of very-low-density lipoprotein and its response to hormones and sulphonylureas. Biochem. J. 284: 457-462

40 Lankester D. L., Brown A. M. and Zammit V. A. (1998) Use of cytosolic triacylglycerol hydrolysis products and of exogenous fatty acid for the synthesis of triacylglycerol secreted by cultured rat hepatocytes. J. Lipid Res. 39: 1889-1895

41 Yang L.-Y., Kuksis A., Myher J. J. and Steiner G. (1995) Origin of triacylglycerol moiety of plasma very low density lipoproteins in the rat: structural studies. J. Lipid Res. 36: 125-136

42 Yang L.-Y., Kuksis A., Myher J. J. and Steiner G. (1996) Contribution of de novo fatty acid synthesis to very low density lipoprotein triacylglycerols: evidence from mass isotopomer distribution analysis of fatty acids synthesized from $\left[{ }^{2} \mathrm{H}_{6}\right]$ ethanol. J. Lipid Res. 37: 262-274

43 Gibbons G. F., Khurana R., Odwell A. and Seelaender M. C. (1994) Lipid balance in HepG2 cells: active synthesis and impaired mobilization. J. Lipid Res. 35: 1801-1808

44 Lehner R. and Vance D. E. (1999) Cloning and expression of a cDNA encoding a hepatic microsomal lipase that mobilizes stored triacylglycerol. Biochem. J. 341: 1-10

45 Pease R. J., Wiggins E. D., Saggerson E. D., Tree J. and Gibbons G. F. (1999) Metabolic characteristics of a human hepatoma cell line stably transfected with hormone-sensitive lipase. Biochem. J. 341: 453-460

46 Lehner R. and Verger R. (1997) Purification and characterization of a porcine liver microsomal triacylglycerol hydrolase. Biochemistry 36: $1861-1868$

47 Blanchette-Mackie E. J., Dwyer T., Coxey R. A., Takeda T., Rondinone C. M., Theodorakis J. L. et al. (1995) Perilipin is located on the surface layer of intracellular lipid droplets in adipocytes. J. Lipid Res. 36: 1211-1226

48 Horton J. D., Shimano H., Hamilton R. L., Brown M. S. and Goldstein J. L. (1999) Disruption of LDL receptor gene in transgenic SREBP-1a mice unmasks hyperlipidemia resulting from production of lipid-rich VLDL. J. Clin. Invest. 103: 1067-1076

49 Lehner R., Cui Z. and Vance D. E. (1999) Subcellullar localization, developmental expression and characterization of a liver triacylglycerol hydrolase. Biochem. J. 338: 761-768 
50 Matsumshima M., Inoue H., Ichinose M., Tsukada S., Miki K., Kirokawa K. et al. (1991) The nucleotide and deduced amino acid sequences of porcine liver proline- beta-naphthylamidase. Evidence for the identity with carboxylesterase. FEBS Lett. 293: 37-41

51 Satoh T., and Hosakawa M. (1998) The mammalian carboxylesterases: from molecules to functions. Annu. Rev. Pharmacol. Toxicol. 38: 256-288

52 Alam M., Ho S., Vance D. E., and Lehner R. (2002) Heterologous expression, purification, and characterization of human triacylglycerol hydrolase. Protein Expression Purif. 24: $33-42$

53 Dolinsky V. W., Sipione S., Lehner R. and Vance D. E. (2001) The cloning and expression of a murine triacylglycerol hydrolase cDNA and the structure of its corresponding gene. Biochim. Biophys. Acta 1532: $162-172$

54 Hosokawa M., Maki T. and Satoh T. (1987) Multiplicity and regulation of hepatic microsomal carboxylesterases in rats. Mol. Pharmacol. 31: 579-584

55 Robbi M., Beaufay H. and Octave J. N. (1990) Nucleotide sequence of cDNA coding for rat liver pI 6.1 esterase (ES-10), a carboxylesterase located in the lumen of the endoplasmic reticulum. Biochem. J. 269: 451-458

56 Morgan E. W., Yan B., Greenway D. and Parkinson A. (1994) Regulation of two rat liver microsomal carboxylesterase isozymes: species differences, tissue distribution, and the effects of age, sex, and xenobiotic treatment of rats. Arch. Biochem. Biophys. 315: 513-526

57 Ghosh S., Mallonee,D. H., Hylemon P. B. and Grogan W. M. (1995) Molecular cloning and expression of rat hepatic neutral cholesteryl ester hydrolase. Biochim. Biophys. Acta 1259: 305-312

58 Alam M., Vance D. E. and Lehner R. (2002) Structure-function analysis of human triacylglycerol hydrolase by site-directed mutagenesis: identification of the catalytic triad and a glycosylation site. Biochemistry 41: 6679-6687

59 McLean J., Fielding C. J., Drayna D., Dieplinger H., Baer B., Kohr W. et al. (1986) Cloning and expression of human lecithin-cholesterol acyltransferase cDNA. Proc. Natl. Acad. Sci. USA 83: 2335-2339

60 Drayna D.A., Jarnagin A.S., McLean J., Henzel W., Kohr W., Fielding C. et al. (1987) Cloning and sequencing of human cholesteryl ester transfer protein cDNA. Nature 327: 632-634

61 Holm C., Kirchgessner T. G., Svenson K. L., Fredrikson G., Nilsson S., Miller C. G. et al. (1988) Hormone-sensitive lipase: sequence, expression, and chromosomal localization to 19 cent-q13.3. Science 241: 1503-1506

62 Kissel J. A., Fontaine R. M., Turck C. W., Brockman H. L. and Hui D. Y. (1989) Molecular cloning and expression of cDNA for rat pancreatic cholesterol esterase. Biochim. Biophys. Acta 1006: $227-236$

63 Noshiro M. and Okuda K. (1990) Molecular cloning and sequence analysis of cDNA encoding human cholesterol 7 alpha-hydroxylase. FEBS Lett. 268: 137-140

64 Au-Young J. and Fielding C. J. (1992) Synthesis and secretion of wild-type and mutant human plasma cholesteryl ester transfer protein in baculovirus-transfected cells: the carboxyl-terminal region is required for both lipoprotein binding and catalysis of transfer. Proc. Natl. Acad. Sci. USA 89: 40944098

65 Robbi M. and Beaufay H. (1991) The COOH terminus of several liver carboxylesterases targets these enzymes to the lumen of the endoplasmic reticulum. J. Biol. Chem. 266: 20498-20503

66 Bencharit S., Morton C. L., Howard-Williams E. L., Danks M. K., Potter P. M. and Redinbo M. R. (2002) Structural insights into CPT-11 activation by mammalian carboxylesterases. Nat. Struct. Biol. 9: 337-342
67 Bencharit S., Morton C. L., Xue Y., Potter P. M. and Redinbo M. R. (2003) Structural basis of heroin and cocaine metabolism by a promiscuous human drug-processing enzyme. Nat. Struct. Biol. 10: 349-356

68 Bencharit S., Morton C. L., Hyatt J. L., Kuhn P., Danks M. K., Potter P. M. et al. (2003) Crystal structure of human carboxylesterase 1 complexed with the Alzheimer's drug tacrine. From binding promiscuity to selective inhibition. Chem. Biol. 10: $341-349$

69 Wong H. and Schotz M. C. (2002) The lipase gene family. J. Lipid Res. 43: 993-999

70 Wallace T. J., Kodsi E. M., Langston T. B., Gergis M. R. and Grogan W. M. (2001) Mutation of residues 423 (Met/Ile), 444 (Thr/Met) and 506 (Asn/Ser) confer cholesteryl esterase activity on rat lung carboxylesterase. Ser-506 is required for activation by cAMP-dependent protein kinase. J. Biol. Chem. 276: $33165-33174$

71 Ollis D. L., Cheah E., Cygler M., Dijkstra B., Frolow F., Franken S. M., et al. (1992) The $\alpha / \beta$ hydrolase fold. Protein Eng. 5: 197-211

72 Pfister K., Bosshard N., Zopfi M. and Gitzelmann R. (1988) Egasyn affects the processing of beta-glucuronidase in mouse liver. Biochem. J. 255: $825-832$

73 Yue C. C., Muller-Greven P., Dailey P., Lozanski G., Anderson V. and Macintyre S. (1996) Identification of a C-reactive protein binding site in two hepatic carboxylesterases capable of retaining C-reactive protein within the endoplasmic reticulum. J. Biol. Chem. 271: 22245-22250

74 Lee W., Ryu J., Hah J., Tsujita T. and Jung C. Y. (2000) Association of carboxyl esterase with facilitative glucose transporter isoform 4 (GLUT4) intracellular compartments in rat adipocytes and its possible role in insulininduced GLUT4 recruitment. J. Biol. Chem. 275: 1004110046

75 Becker A., Bottcher A., Lackner K.J., Fehringer P., Notka F., Aslanidis C. et al. (1994) Purification, cloning and expression of a human enzyme with acyl coenzyme A: cholesterol acyltransferase activity, which is identical to liver carboxylesterase. Arterioscler. Thromb. 14: 1346-1355

76 Diczfalusy M. A., Bjorkhem I., Einarsson K. and Alexson S. E. (1996) Acyl-coenzyme A:cholesterol O-acyltransferase is not identical to liver microsomal carboxylesterase. Arterioscler. Thromb. Vasc. Biol. 16: 606-610

77 Buhman K. F., Accad M. and Farese R. V. (2000) Mammalian acyl-CoA:cholesterol acyltransferases. Biochim. Biophys. Acta 1529: $142-154$

78 Harrison E. H. (2000) Lipases and carboxylesterases: possible roles in the hepatic utilization of vitamin A. J. Nutr. 130: $340 \mathrm{~S}-344 \mathrm{~S}$

79 Gilham D., Ho S., Rasouli M., Martres P., Vance D. E. and Lehner R. (2003) Inhibitors of hepatic microsomal triacylglycerol hydrolase decrease very low density lipoprotein secretion. FASEB J. 17: 1685-1687

80 Leung D., Hardouin C., Boger D. L. and Cravatt B. F. (2003) Discovering potent and selective reversible inhibitors of enzymes in complex proteomes. Nat. Biotech. 21: 687-691

81 Tsujita T. and Okuda H. (1992) Fatty acid ethyl ester synthase in rat adipose tissue and its relationship to carboxylesterase. J. Biol. Chem. 267: 23489-23494

82 Diczfalusy M. A., Bjorkhem I., Einarsson C., Hillebrant C. G. and Alexson S. E. (2001) Characterization of enzymes involved in formation of ethyl esters of long-chain fatty acids in humans. J. Lipid Res. 42: 1025-1032

83 Pfutzer R. H., Tadic S. D., Li H. S., Thompson B. S., Zhang J. Y., Ford M. E. et al. (2002) Pancreatic cholesterol esterase, ES-10, and fatty acid ethyl ester synthase III gene expression are increased in the pancreas and liver but not in the brain or heart with long-term ethanol feeding in rats. Pancreas 25: $101-106$ 
84 Brzezinski M. R., Abraham T. L., Stone C. L., Dean R. A. and Bosron W. F. (1994) Purification and characterization of a human liver cocaine carboxylesterase that catalyzes the production of benzoylecgonine and the formation of cocaethylene from alcohol and cocaine. Biochem. Pharmacol. 48: 1747-1755

85 Hummerickhouse R., Lohrbach K., Li L., Bosron W. F. and Dolan M. E. (2000) Characterization of CPT-11 hydrolysis by human liver carboxylesterase isoforms hCE-1 and hCE-2. Cancer Res. 60: 1189-1192

86 Wu M. H., Yan B., Humerickhouse R. and Dolan M. E. (2002) Irinotecan activation by human carboxylesterases in colorectal adenocarcinoma cells. Clin. Cancer Res. 8: 2696-2700

87 Xie M., Yang D., Wu M., Xue B. and Yan B. (2003) Mouse liver and kidney carboxylesterase (M-LK) rapidly hydrolyzes antitumor prodrug irinotecan and the $\mathrm{N}$-terminal three quarter sequence determines substrate selectivity. Drug Metab. Disp. 31: $21-27$

88 Shibata F., Takagi Y., Kitajima M., Kuroda T. and Omura T. (1993) Molecular cloning and characterization of a human carboxylesterase gene. Genomics 17: 76-82

89 Langmann T., Becker A., Aslanidis C., Notka F., Ullrich H., Schwer H. et al. (1997) Structural organization and characterization of the promoter region of a human carboxylesterase gene. Biochim. Biophys. Acta 1350: $65-74$

90 Zschunke F., Salmassi A., Kreipe H., Buck F., Parwaresch M. R. and Radzun H. J. (1991) cDNA cloning and characterization of human monocyte/macrophage serine esterase-1. Blood 78: $506-512$

91 Kroetz D. L., McBride O. W. and Gonzalez F. J. (1993) Glycosylation-dependent activity of baculovirus-expressed human liver carboxylesterases: cDNA cloning and characterization of two highly similar enzyme forms. Biochemistry 32: 11606-11617

92 Eisenhardt E. and von Deimling O. (1982) Interstrain variation of esterase-22, a new isozyme of the house mouse. Comp. Biochem. Physiol. 73B: 719

93 Ovnic M. Swank R. T., Fletcher C., Zhen L., Novak E. K., Baumann H. et al. (1991) Characterization and functional expression of a cDNA encoding egasyn (esterase-22): the endoplasmic reticulum-targeting protein of beta-glucuronidase. Genomics 11: 956-967

94 Womack J. E. (1975) Esterase-6 (Es-6) in laboratory mice: hormone-influenced expression and linkage relationship to oligosyndactylism (Os), esterase-1 (Es-1) and esterase-2 (Es2) in chromosome 8. Biochem. Genet. 13: 311-321

95 Ovnic M., Tepperman K., Medda S., Elliot R. W., Stephenson D. A., Grant S. G. et al. (1991) Characterization of a murine cDNA encoding a member of the carboxylesterase multigene family. Genomics 9: 344-354

96 Peters J. (1982) Nonspecific esterases of Mus musculus. Biochem. Genet. 20: 585-606

97 Ellinghaus P., Seedorf U. and Assman G. (1998) Cloning and sequencing of a novel murine liver carboxylesterase cDNA. Biochim. Biophys. Acta 1397: 175-179

98 Murakami K., Takagi Y., Mihara K. and Omura T. (1993) An isozyme of microsomal carboxyesterases, carboxyesterase $\mathrm{Sec}$, is secreted from rat liver into the blood. J. Biochem. 113: $61-66$

99 Ghosh S. (2000) Cholesteryl ester hydrolase in human monocyte/macrophage: cloning, sequencing and expression of fulllength cDNA. Physiol. Genomics 2: 1-8

100 Yan B., Yang D., Brady M. and Parkinson A. (1994) Rat kidney carboxylesterase. Cloning, sequencing, cellular localization and relationship to rat liver hydrolase. J. Biol. Chem. 269: 29688-29696

101 Yan B., Yang D., Brady M. and Parkinson A. (1995) Rat testicular carboxylesterase: cloning, cellular localization and relationship to liver hydrolase A. Arch. Biochem. Biophys. 316: 899-908
102 Gaustad R., Berg T. and Fonnum F. (1992) Heterogeneity of carboxylesterases in rat liver cells. Biochem. Pharmacol. 44: 827-829

103 Bartlett S. M. and Gibbons G. F. (1988) Short- and longerterm regulation of very-low-density lipoprotein secretion by insulin, dexamethasone and lipogenic substrates in cultured hepatocytes. A biphasic effect of insulin. Biochem. J. 249: $37-43$

104 Rashid K. A., Hevi S., Chen Y., Le Cahérec F. L. and Chuck S. L. (2002) A proteomic approach identifies proteins in hepatocytes that bind nascent apolipoprotein B. J. Biol. Chem. 277: 22010-22017

105 Reference removed in proof

106 Lin M., Arbeeny C., Bergquist K., Kienzle B., Gordon D. A. and Wetterau J. R. (1994) Cloning and regulation of hamster microsomal triglyceride transfer protein. J. Biol. Chem. 269: 29138-29145

107 Yang L.-Y. and Kuksis A. (1991) Apparent convergence (at 2monoacylglycerol level) of phosphatidic acid and 2-monoacylglycerol pathways of synthesis of chylomicron triacylglycerols. J. Lipid Res. 32: 1173-1186

108 Shoulders C. C, Brett D. J., Bayliss J. D., Narcisi T. M. E., Jaruz A., Grantham T. T. et al. (1993) Abetalipoproteinemia is caused by defects of the gene encoding the $97 \mathrm{kDa}$ subunit of a microsomal triglyceride transfer protein. Hum. Mol. Genet. 2: $2109-2116$

109 Tarugi P., Ballarini G., Pinotti B., Franchini A., Ottaviani E. and Calandra S. (1998) Secretion of apoB- and apoA-I-containing lipoproteins by chick kidney. J. Lipid Res. 39: 731 - 743

110 Boren J., Veniant M. M. and Young S. G. (1998) Apo B100containing lipoproteins are secreted by the heart. J. Clin. Invest. 101: 1197-1202

111 Veniant M. M., Nielsen L. B., Boren J. and Young S. G. (1999) Lipoproteins containing apolipoprotein B-100 are secreted by the heart. Trends Cardiovasc. Med. 9: 103-107

112 Khoo J. C., Reue K., Steinberg D. and Schotz M. C. (1993) Expression of hormone-sensitive lipase mRNA in macrophages. J. Lipid Res. 34: 1969-1974

113 Reue K., Cohen R. D. and Schotz M. C. (1997) Evidence for hormone-sensitive lipase mRNA expression in human monocyte/macrophages. Arterioscler. Thromb. Vasc. Biol. 17: $3428-3432$

114 Escary J. L., Choy H. A., Reue K. and Schotz M. C. (1998) Hormone-sensitive lipase overexpression increases cholesteryl ester hydrolysis in macrophage foam cells. Arterioscler. Thromb. Vasc. Biol. 18: 991-998

115 Okazaki H., Osuga J., Tsukamoto K., Isoo N., Kitamine T., Tamura Y. et al. (2002) Elimination of cholesterol ester from macrophage foam cells by adenovirus-mediated gene transfer of hormone-sensitive lipase. J. Biol. Chem. 277: 31893-31899

116 Jepson C. A., Harrison J. A., Kraemer F. B. and Yeaman S. J. (1996) Down-regulation of hormone-sensitive lipase in sterol ester-laden J774.2 macrophages. Biochem. J. 318: 173- 177

117 Harte R. A., Hulten L. M., Lindmark H., Reue K., Schotz M. C., Khoo J. et al. (2000) Low level expression of hormonesensitive lipase in arterial macrophage-derived foam cells: potential explanation for low rates of cholesteryl ester hydrolysis. Atherosclerosis 149: 343-350

118 Contreras J. A. (2002) Hormone-sensitive lipase is not required for cholesteryl ester hydrolysis in macrophages. Biochem. Biophys. Res. Commun. 292: 900-903

119 Ghosh S., St Clair R. W. and Rudel L. L. (2003) Mobilization of cytoplasmic CE droplets by overexpression of human macrophage cholesteryl ester hydrolase. J. Lipid Res. 44: $1833-1840$

120 Mikhailov A. T. and Torrado M. (2000) Carboxylesterases moonlight in the male reproductive tract: a functional shift pivotal for male fertility. Fron. Biosci. 5: 53-62 
121 Douglas D. N., Dolinsky V. W., Lehner R. and Vance D. E. (2001) A role for Sp1 in the transcriptional regulation of hepatic triacylglycerol hydrolase in the mouse. J. Biol. Chem. 276: $25621-25630$

122 Nataranjan R., Ghosh S. and Grogan W. M. (1998) Molecular cloning of the promoter for rat hepatic neutral cholesterol ester hydrolase: evidence for transcriptional regulation by sterols. Biochem. Biophys. Res. Commun. 243: $349-355$

123 Trickett J. I., Patel D. D., Knight B. L., Saggerson E. D., Gibbons G. F. and Pease R. J. (2001) Characterization of the rodent genes for arylacetamide deacetylase, a putative microsomal lipase, and evidence for transcriptional regulation. J. Biol. Chem. 276: $39522-39532$

124 Suske G. (1999) The Sp-family of transcription factors. Gene 238: $291-300$

125 Dynan W. S. and Tjian R. (1983) The promoter-specific transcription factor Sp1 binds to upstream sequences in the SV40 early promoter. Cell $35: 79-87$

126 Anderson B. M. and Freytag, S. O. (1991) Synergistic activation of a human promoter in vivo by transcription factor $\mathrm{Sp} 1$. Mol. Cell. Biol. 11: 19335-19343

127 Langmann T., Aslandis C., Schuierer M. and Schmitz G. (1997) Differentiation-dependent expression of a human carboxylesterase in monocytic cells and transcription factor binding to the promoter. Biochem. Biophys. Res. Commun. 230: $215-219$

128 Dolinsky V. W., Gilham D., Hatch G. M., Agellon L. B., Lehner R. and Vance D. E. (2003) Regulation of triacylglycerol hydrolase expression by dietary fatty acids and peroxisomal proliferator-activated receptors. Biochim. Biophys. Acta 1635: $20-28$

129 Oliver W. R., Shenk J. L., Snaith M. R., Russell C. S., Plunket K. D., Bodkin N. L. et al. (2001) A selective peroxisome proliferator-activated receptor delta agonist promotes reverse cholesterol transport. Proc. Natl. Acad. Sci. USA 98: 53065311

130 Fruchart J. C., Puriez P. and Staels B. (1999) Peroxisome proliferator-activated receptor-alpha activators regulate genes governing lipoprotein metabolism, vascular inflammation and atherosclerosis. Curr. Opin. Lipidol. 10: 245-257

131 Staels B., Dallongeville J., Auwerx J., Schoonjans K., Leitersdorf E. and Fruchart J.-C. (1998) Mechanism of action of fibrates on lipid and lipoprotein metabolism. Circulation 98: 2088-2093

132 Poole M., Bridgers K., Alexson S. E. and Corton J. C. (2001) Altered expression of the carboxylesterases ES-4 and ES-10 by peroxisome proliferator chemicals. Toxicology 165: 109-119

133 Ashour M.-B. A., Moody D. E. and Hammock B. D. (1987) Apparent induction of microsomal carboxylesterase activities in tissues of clofibrate-fed mice and rats. Toxicol. Appl. Pharmacol. 89: 361-369

134 Hosokawa M. and Satoh T. (1993) Differences in the induction of carboxylesterase isozymes in rat liver microsomes by perfluorinated fatty acids. Xenobiotica 23: $1125-1133$

135 Parker A. G., Pinot F., Grant D. F., Spearow J. and Hammock B. D. (1996) Regulation of mouse liver microsomal esterases by clofibrate and sexual hormones. Biochem. Pharmacol. 51: $677-685$

136 Huang G. S., Yang S.-M., Hong M.-Y., Yang P.-C. and Liu Y.C. (2000) Differential gene expression of livers from ApoE deficient mice. Life Sci. 68: 19-28

137 Ghosh S. Nataranjan R., Pandak W. M., Hylemon P. B. and Grogan W. M. (1998) Regulation of hepatic neutral cholesteryl ester hydrolase by hormones and changes in cholesterol flux. Am. J. Physiol. 274: G662-G668

138 Natarajan R., Ghosh S. and Grogan W. M. (1999) Regulation of the rat neutral cytosolic cholesteryl ester hydro- lase promoter by hormones and sterols: a role for nuclear factor-Y in the sterol-mediated response. J. Lipid Res. 40: 20912098

139 Dolinsky V. W., Douglas D. N., Lehner R. and Vance D. E. (2004) Dexamethasone down-regulates the expression of triacylglycerol hydrolase and triacylglycerol lipolysis in the livers of mice. Biochem. J. 378: 967-974

140 Glenny H. P. and Brindley D. N. (1978) The effects of cortisol, corticotropin and thyroxine on the synthesis of glycerolipids and on the phosphatidate phosphohydrolase activity in rat liver. Biochem. J. 176: 777-784

141 Krausz Y., Bar-On H. and Shafrir E. (1981) Origin and pattern of glucocorticoid-induced hyperlipidemia in rats. Dose-dependent bimodal changes in serum lipids and lipoproteins in relation to hepatic lipogenesis and tissue lipoprotein lipase activity. Biochim. Biophys. Acta 663: 69-82

142 Cole T. G., Wilcox H. G. and Heimberg M. (1982) Effects of adrenalectomy and dexamethasone on hepatic lipid metabolism. J. Lipid Res. 23: 81-91

143 Staels B., vanTol A., Chan L., Verhoven G. and Auwerx J. (1991) Variable effects of different corticosteroids on plasma lipids, apolipoproteins and hepatic apolipoprotein mRNA levels in rats. Arterioscler. Throm. 11: 760-769

144 Hosokawa M., Hattori K. and Satoh T. (1993) Differential responses of rat hepatic microsomal carboxylesterase isozymes to glucocorticoids and pregnenolone 16 alpha-carbonitrile. Biochem. Pharmacol. 45: 2317-2322

145 Zhu W., Song L., Zhang H., Matoney L., Lecluyse E. and Yan B. (2000) Dexamethasone differentially regulates expression of carboxylesterase genes in humans and rats. Drug Metab. Disp. 28: 186-191

146 Morimoto Y., Arisue K. and Yamamura Y. (1977) Relationship between circadian rhythm of food intake and that of plasma corticosterone and effect of food restriction on circadian adrenocortical rhythm in the rat. Neuroendocrinol. 23: $212-222$

147 Shiraishi I., Honma K.-I., Honma S. and Hiroshige T. (1984) Ethosecretogram: relation of behavior to plasma corticosterone in freely moving rats. Am. J. Physiol. 247: R40-R45

148 Fukuda H., Katsurada A. and Iritani N. (1985) Diurnal variations of lipogenic enzymes, their substrate and effector levels, and lipogenesis from tritiated water in rat liver. Biochim. Biophys. Acta 835: $163-168$

149 Xu Z. X. and Rooney S. A. (1997) Glucocorticoids increase fatty-acid synthase mRNA stability in fetal rat lung. Am. J. Physiol. 272: L860-864

150 Knox A. M., Sturton R. G., Cooling J. and Brindley D. N. (1979) Control of hepatic triacylglycerol synthesis. Diurnal variations in hepatic phosphatidate phosphohydrolase activity and in the concentrations of circulating insulin and corticosterone in rats. Biochem. J. 180: 441-443

151 Pittner R. A., Fears R. and Brindley D. N. (1985) Interactions of insulin, glucagon and dexamethasone in controlling the activity of glycerol phosphate acyltransferase and the activity and subcellular distribution of phosphatidate phosphohydrolase in cultured rat hepatocytes. Biochem. J. 230: $525-$ 534

152 Sidossis L. S., Mittendorfer B., Walser E., Chinkes D. and Wolfe R. R. (1998) Hyperglycemia-induced inhibition of splanchnic fatty acid oxidation increases hepatic triacylglycerol secretion. Am. J. Physiol. 275: E798-E805

153 Rosmond R., Dallman M. F. and Bjorntorp P. (1998) Stress-related cortisol secretion in men: relationships with abdominal obesity and endocrine, metabolic and hemodynamic abnormalities. J. Clin. Endocrinol. Metab. 83: 1853-1859

154 Dallman M. F., Akana S. F., Bhatnagar S., Bell M. E. and Strack A. M. (2000) Bottomed out: metabolic significance of the circadian trough in glucocorticoid concentrations. Int. J. Obes. Relat. Metab. Disord. 24: S40-S46 
155 Ruan H., Miles P. D. G., Ladd C. M., Ross K., Golub T. R., Olefsky J. M. et al. (2002) Profiling gene transcription in vivo reveals adipose tissue as an immediate target of tumor necrosis factor-alpha: implications for insulin resistance. Diabetes 51: $3176-3188$
156 Verine A., Le Petit-Thevenin J., Panicot-Dubois L., Valette A. and Lombardo D. (2001) Phosphorylation of the oncofetal variant of the human bile salt-dependent lipase. Identification of phosphorylation site and relation with secretion process. J. Biol. Chem. 276: 12356-12361

\section{(17) To access this journal online: \\ (4P) http://www.birkhauser.ch}

